\title{
Securitization and Real Investment in Incomplete Markets*
}

\author{
Vishal Gaur $†$ Sridhar Seshadri $; \quad$ Marti G. Subrahmanyam ${ }^{\S}$
}

First version: August 15, 2007. This version: August 27, 2009.

\begin{abstract}
We study the impact of financial innovations on real investment decisions within the framework of an incomplete market economy comprised of firms, investors, and an intermediary. The firms face unique investment opportunities that arise in their business operations and can be undertaken at given reservation prices. The cash flows thus generated are not spanned by the securities traded in the financial market, and cannot be valued uniquely. The intermediary purchases claims against these cash flows, pools them together, and sells tranches of primary or secondary securities to the investors.

We derive necessary and sufficient conditions under which projects are undertaken due to the intermediary's actions, and firms are amenable to the pool proposed by the intermediary, compared to the no-investment option or the option of forming alternative pools. We also determine the structure of the new securities created by the intermediary and identify how it exploits the arbitrage opportunities available in the market. Our results have implications for valuation of real investments, synergies among them, and their financing mechanisms. We illustrate these implications using an example of inventory decisions under random demand.
\end{abstract}

Keywords: Incomplete markets, Securitization, Financial innovation, Real options, Project financing.

\footnotetext{
${ }^{*}$ The authors thank John Birge, Kose John, Roy Radner, Rangarajan Sundaram, the associate editor, three anonymous reviewers, and seminar participants at Columbia University, Ente Einaudi, Rome, University of Melbourne, New York University, Rutgers University, the University of Venice, the Caesarea Center, Herzliya, Israel, Stanford University, the 2004 European Finance Association meeting in Maastricht, the 2004 INFORMS meeting in Denver, and the 2005 European FMA Conference in Siena.

${ }^{\dagger}$ Johnson Graduate School of Management, Cornell University, 321 Sage Hall, Ithaca, NY 14853-6201. Email: vg77@cornell.edu.

${ }^{\ddagger}$ McCombs School of Business, University of Texas, 1 University Station, Austin, TX 78712. Email: seshadris@mccombs.utexas.edu

${ }^{\S}$ Leonard N. Stern School of Business, New York University, 44 West 4th St., New York, NY 10012. Email: msubrahm@stern.nyu.edu.
} 


\section{Introduction}

In the standard paradigm of financial economics, the value of a project is derived from capital market prices based on the twin assumptions that the cash flows from the project can be replicated in the financial market and that all agents are price-takers with respect to the market for financial claims. However, firms often have opportunities that are unique to them and generate future cash flows that cannot be replicated by transactions in the existing securities in the market. Such opportunities can include capacity expansion, inventory procurement, new product launches, setting up of new retail stores and supply chain infrastructure, etc. We collectively call such opportunities as real investments, real assets or projects, since they involve the creation of physical rather than financial assets.

When markets are incomplete, the value of a real asset cannot always be uniquely computed using capital market prices, but only bounds can be placed on its present value. Projects whose values are unambiguously greater than their reservation prices are financed, and those whose values unambiguously fall below their respective reservation prices are rejected. However, nothing specific can be said when the reservation price lies between these price bounds. In such cases, do innovations in capital markets permit investments in real assets that would otherwise not occur because they are too costly to finance? In other words, do such innovations impact real investment decisions, aside from providing arbitrage opportunities to the innovators? Our paper addresses these questions.

Three alternative mechanisms may be responsible for the improved attractiveness of projects as a result of financial innovations. The first is the effect of the innovation on the amelioration of information asymmetry between the investors and the entrepreneur/manager of the firm. The second is a reduction in market frictions, such as transaction costs, as a result of the innovation. The third is through improved matching of the project cash flows to the needs of investors in various states of the nature, in the context of an incomplete financial market. The first two mechanisms have been studied in the literature in a variety of models dealing with financial innovation, financial intermediation, or securitization. We focus on the third mechanism, which has not been adequately studied thus far, using the no-arbitrage principle without making explicit assumptions about transaction 
costs or information asymmetry. Moreover, while models in the literature describe innovation in the context of existing assets owned by firms, we examine its implications for investment in new real assets.

The specific financial innovation we consider is securitization, although our framework lends itself to the analysis of other financial innovations, such as venture capital and private equity. Since its beginning in the 1970s, the phenomenon of securitization is now widespread in financial markets: mortgages, credit card receivables and various types of corporate debt instruments have been securitized using a variety of alternative structures. The common feature of these structures is that an intermediary purchases claims on cash flows issued by various entities, pools these claims into a portfolio, and then tranches them into marketable securities that cater to the investment needs of particular clienteles of investors.

To take the example of collateralized debt obligations (CDOs), the basic structure is that a financial intermediary sets up a special purpose vehicle (SPV) that buys a portfolio of debt instruments - bonds and/or loans - and adds credit derivatives on individual "names." This is referred to as pooling. The SPV then issues various claims against the pooled portfolio, which enjoy different levels of seniority ranging from a super-senior claim, i.e., a high-grade AAA claim, which has a negligible probability of not meeting its promised payment, to a medium-grade mezzanine claim, say rated $\mathrm{BBB}+$, which has a low but non-trivial probability of such default, and finally, to an equity security, which is viewed as risky. The structuring of claims to match investor tastes and risk preferences is referred to as tranching and the claims are referred to as tranches. ${ }^{1}$

In our model, securitization transactions take place among three types of agents, firms, investors, and financial intermediaries. Firms have opportunities to create unique assets at given reservation prices, and seek to maximize the time-zero value of these assets. Investors are utility maximizers. Intermediaries purchase claims from firms that are fully backed by project cash flows, and issue two types of securities that are sold to investors, those that are within the span of the financial market (marketable securities), and those that are not spanned by the market (secondary securities). Throughout our analysis, we assume that all agents are price-takers, i.e., these transactions are not

\footnotetext{
${ }^{1}$ This description is a slight simplification of the real structure in practice. See Tavakoli (2003) for details.
} 
large enough to influence the prices of existing securities traded in the market. In an arbitrage-free setting, we study whether the transactions undertaken by the intermediary create value for firms and investors. The value for firms is created by permitting investments in real assets that would not be undertaken otherwise. The value to investors is created by satisfying demand for consumption better than by simply trading primary securities in the financial market.

The main results of our paper are as follows. We first consider only pooling. In this setting, the financial intermediary pools cash flows from the assets of several firms or divisions of a firm, and issues only such securities as are within the span of the market. Firms may not behave altruistically, so we allow them to form coalitions with some or all of the other firms in order to seek financing. Therefore, the outcome of the firms' decision problem can be modeled as a cooperative game. We show that the cooperative game results in the creation of a maximal pool of assets. This pool maximizes the value enhancement provided by pooling, and may or may not consist of all assets of all firms. We prove a simple condition, given by the set of pricing measures and the cash flows and reservation prices of new assets, that is necessary and sufficient for a firm to participate in the game. Thus, we show that pure pooling (sans tranching) can not only provide value enhancement, but also sustain the synergy through a price mechanism.

We then consider joint pooling and tranching. Through tranching, the intermediary can customize securities to the needs of investors. Therefore, we expect pooling and tranching to provide greater value than pure pooling. We show that the additional value can be characterized using the structure of securities created by the intermediary. These securities can have up to three components; a component that is marketable, a second type that exploits arbitrage opportunities available in the market due to the intermediary's special ability to design and sell securities to a subset of investors, and a third component that is the remainder of the asset pool. The presence or absence of these three components in the tranching solution has a direct bearing upon the composition of the asset pool, and therefore, upon value creation due to financing additional projects. We find that tranching plays a somewhat different role than pooling. While it increases the value of the projects financed similar to pooling, it could also result in more selective financing. Due to this effect, the set of viable projects could shrink or expand, when compared to pooling alone. 
Our results imply that the optimal real investment decision of a firm depends on the form of financing chosen by it. In a complete market, there can be no benefit from pooling and tranching. The standard approaches of asset pricing and valuation of real options are equivalent to our model for the pricing of traded assets, but do not show the value of securitization for non-traded assets in incomplete markets. Thus, the value creation studied in our paper is complementary to the mechanisms of operational flexibility and operational hedging studied in the operations management literature since it is based on pricing of non-marketed risks, whereas models of operational flexibility have generally been studied in the context of a complete market.

Real asset securitization, asset monetization, and off-balance-sheet financing have been used by many firms in practice. For instance, firms in the pharmaceuticals and credit card industries, as well as Peoplesoft Corp., General Motors Corp., Ford Motor Company, and Scott Paper Co. have spun off divisions/subsidiaries as separate companies (Fink (2002), Gorton and Souleles (2005), Gourdon and Reynolds (2001)). The noted benefits of asset monetization and setting up SPVs include reduction of debt, reduction of cost of capital, focus on core competency, and increased ability to invest in additional opportunities. However, these examples relate to selling assets already owned by a firm or a bank, and thus, do not consider the valuation implications of securitization on new investments decisions. They also do not consider the optimal composition or the benefits of pooling and tranching. Our paper focuses on these aspects. Moreover, alternative to securitization, firms may consider other types of financing for new projects, such as issuance of debt or equity. Our paper does not evaluate the costs and benefits of these alternative approaches. It only studies securitization as a form of financing in depth.

This paper is organized as follows: in $\S 2$, we review the related literature on incomplete markets and securitization; in $\S 3$, we present the model setup and assumptions; in $\S 4$, we analyze the conditions under which there is value in pooling, and firms willingly participate in the creation of the asset pool; in $\S 5$, we analyze the value in joint pooling and tranching; $\S 6$ presents a numerical example illustrating the results of our paper for a prototypical inventory optimization problem; and in $\S 7$, we conclude the paper with a discussion of the limitations and implications of our analysis. An appendix compares our model with the capital asset pricing model (CAPM) and also contains 
all the proofs.

\section{Literature Review}

Several real investment decisions have been studied in the literature in the areas of operations management and real options, under varying assumptions on asset pricing. Kogut and Kulatilaka (1994), Huchzermeier and Cohen (1996) and Kouvelis (1999) investigate the effect of exchange rate uncertainty in a global production/distribution network; Smith and McCardle (1999) analyze real options in a multi-period oil drilling project; and Birge (2001) determines value maximization for a multi-period capacity planning model. All these papers assume market completeness and risk neutral decision-makers. Another set of papers, Buzacott and Zhang (2004), Li et al. (2005) and Birge and $\mathrm{Xu}(2005)$, characterize the interaction between operational and financial decisions in the context of market frictions such as bankruptcy and costly debt. Several other papers apply preference based valuation to study operational and financial hedging for risk-averse decision-makers; these include Van Mieghem (2003), Gaur and Seshadri (2005), Dong and Liu (2007), and Ding et al. (2007).

Our paper contributes to this research by examining real investment decisions in incomplete markets, without making assumptions about market frictions or preference-based valuation. Thus, in our model, firms face the problem of ambiguous valuation of future cash flows. We study how pooling and tranching provide value enhancement and affect real investment decisions under uncertainty. In this way, our paper differs from the literature cited above by considering market incompleteness as a source of interaction between operational and financial decisions. We show that market incompleteness affects operational decisions because the value of such decisions may no longer be additive, and this is a key input for stochastic optimization models.

In the literature on incomplete markets, three approaches have been adopted for pricing contingent claims, through bounds based on no-arbitrage, preference-based approaches that impose restrictions on the utility functions of consumers, and approximate arbitrage-based arguments. We apply the first approach, i.e., the arbitrage-based pricing approach of Harrison and Kreps (1979). 
In this approach, the assets whose cash flows are not spanned by the existing market do not have a unique price, but have price bounds based on the no-arbitrage principle because the pricing measure is not unique, or equivalently, the investors do not have equal marginal utility growth rates in all states of nature. Cochrane (2001) calls this approach as the discount factor representation, and shows that it is equivalent to the beta representation as well as the mean-variance representation. Thus, we are not advocating only this approach. Indeed, one can derive an alternative formulation of our framework in the other two approaches by imposing additional restrictions on investor preferences or the reward-to-risk ratio in the market. This would require more assumptions, and thereby, yield more specific conclusions. By using an arbitrage-free framework, the question we are able to answer is whether an intermediary can enhance the value by pooling assets from different firms and tranching them for sale to investors.

Examples of the preference-based approach can be found in the literature on option pricing using preference restrictions, e.g., Perrakis and Ryan (1984), Levy (1985), Ritchken (1985), Ritchken and Kuo (1989), and Mathur and Ritchken (1999). In this stream of literature, coherent risk measures are similar to the valuation approach used by us (Artzner et al. 1999). Examples of the approximate arbitrage-based approach include Shanken (1992), Hansen and Jagannathan (1991), Cochrane and Saa-Requejo (2000), Bernardo and Ledoit (2000), and Bertsimas et al. (2001). In another approach, Mayers $(1973,1976)$ extends the single-period single-factor CAPM framework to the valuation of non-marketable assets, such as human capital. He shows that the exact valuation of such assets for an investor introduces into the standard CAPM a second term that measures the correlation of returns with the non-marketable part of that investor's portfolio. This and other properties shown by Mayers are consistent with our model, although they represent particular parameterizations. ${ }^{2}$

The rationale for the widespread use of securitization in the asset-backed securities market is largely based on two alternative economic explanations, information asymmetry and market

\footnotetext{
${ }^{2}$ In addition, Cerny (1999) studies the minimum martingale measure in the context of no-good-deal bounds of Bernardo and Ledoit (2000), Geanakoplos and Shubik (1990) study the properties of the CAPM in a general equilibrium in incomplete markets, and Weil (1994) analyzes the CAPM with a non-traded asset similar to Mayers (1973).
} 
frictions such as transaction costs. Several researchers have studied the effect of information asymmetry between issuers and investors in the context of securitization. ${ }^{3}$ Pooling and tranching of assets are considered beneficial to both an informed issuer as well as an uninformed investor. The benefits to the issuer result from reducing the incentive to gather information (Glaeser and Kallal 1997), reducing liquidity costs (DeMarzo and Duffie 1999), and designing low-risk debt securities that minimize information asymmetry with investors (DeMarzo 2005). The benefits to the investor result from the ability to split cash flows into a risk-less debt and an equity claim (Gorton and Pennacchi 1990), and reducing the adverse selection problem (DeMarzo 2005).

The role of transaction costs is less clear as shown by Allen and Gale (1991). They examine the incentive for a firm to issue a new security in an incomplete market in the presence of transaction costs. They study the exchange equilibrium that results after the introduction of the new security. The main finding is that even if a single firm amongst many similar ones innovates, the new security results in a readjustment of consumption by investors, which, in turn, leads to a change in asset prices that may benefit similar firms, thus reducing the incentive of any one firm to innovate.

The above papers based on informational asymmetry and transaction costs do not model the firms' decisions to invest in new real assets. Instead, they assume that the assets are given on the balance-sheets of firms. Our paper differs from these streams of literature in this respect. We study the optimal design of both the pool and the tranches, and assess the effect of securitization on real investment. Moreover, we examine market incompleteness as the mechanism for value enhancement.

We draw upon Allen and Gale (1991) by defining the roles of different types of agents analogous to their paper. However, our research objectives and approach differ from theirs in significant ways. First, Allen and Gale study the incentives of one firm to innovate, whereas we study securitization and the role of intermediaries. Second, they allow short sales of new securities by investors in the

\footnotetext{
${ }^{3}$ There is an extensive literature on security design in the context of asymmetric information between "insiders" and investors, which can be traced back to the signalling model proposed by Leland and Pyle (1977). We mention here only those papers that are directly related to the securitization of claims by pooling and tranching. DeMarzo and Duffie (1999) and DeMarzo (2005) provide a more detailed discussion of the broader literature.
} 
context of a general equilibrium approach. We limit short sales of secondary securities, and apply a partial equilibrium approach as is standard in asset pricing. Thus, we can obtain more specific and detailed results, without considering the complex feedback effects that a general equilibrium analysis would entail. This also enables us to study the effect of intermediation and whether it helps more firms to undertake investments (or firms to invest in more projects); if investors could short sell secondary securities, then investors could also intermediate. Therefore, we confine the financial innovation activity to designated financial intermediaries. Lastly, we use a game-theoretic setting to ensure participation by firms in the formation of the asset pool.

\section{$3 \quad$ Model Setup}

We consider an Arrow-Debreu economy in which time is indexed as 0 and 1 . The set of possible states of nature at time 1 is $\Omega=\left\{\omega_{1}, \omega_{2}, \ldots, \omega_{K}\right\}$. For convenience, the state at time zero is denoted as $\omega_{0}$. All agents have the same informational structure: The true state of nature is unknown at $t=0$ and is revealed at $t=1$. Moreover, the $K$ states are a complete enumeration of all possible events of interest, i.e., the subjective probability of any decision-maker is positive for each of these states and adds up to one when summed over all the states. Our model can be extended to a multi-period setting with some added complexity in the notation. However, the basic principles and results derived would still obtain.

\subsection{Securities Market}

Our pricing assumptions are equivalent to standard models in the literature on asset pricing as discussed in $\S 2$. Identical pricing assumptions are also set out by Ekern and Wilson (1974), Magill and Quinzii (2002), and Pliska (1997).

We start with a market in which $N$ primary securities are traded via a financial exchange. Security $n$ has price $p_{n}$ and payoff $S_{n}\left(\omega_{k}\right)$ in state $k$. These securities are issued by firms and purchased by investors through the exchange. The securities market is arbitrage-free and frictionless, i.e., there are no transaction costs associated with the sale or purchase of securities. To keep the 
analysis uncluttered, cash flows are not discounted, i.e., the risk-free rate of interest is zero.

From standard theory, the absence of arbitrage in the financial market is equivalent to postulating that there exists a set, $\Theta$, of risk neutral pricing measures over $\Omega$ under which all traded securities are uniquely priced, i.e., $E_{q}\left[S_{n}\right]=p_{n}$, for all $n$ and for all $q \in \Theta$. It is well known that the set $\Theta$ is spanned by a finite set of independent linear pricing measures. ${ }^{4}$ We label them as $\left\{q_{l}, l=1, \ldots, L\right\}$. In particular, when the set $\Theta$ is a singleton, the market is complete, else it is incomplete.

Not every claim can be priced uniquely in an incomplete market. When a claim cannot be priced uniquely, the standard theory provides bounds for the price of a claim $Z$ that pays $Z\left(\omega_{k}\right)$ in state $k$. Let $V^{-}(Z)=\max \{E[S]: S \leq Z, S$ is attainable $\}$, and let $V^{+}(Z)=\min \{E[S]: S \geq$ $Z, S$ is attainable $\}. V^{-}(Z)$ and $V^{+}(Z)$ are well-defined and finite, and correspond to the lower and upper bounds on the price of the claim $Z$ on the set $\Theta$. Given that $\Theta$ is spanned by a finite set of independent linear pricing measures labeled $\left\{q_{l}, l=1, \ldots, L\right\}$, this can be formalized in the following Lemma.

Lemma 1. (i) $V^{+}(Z)=\max _{l \in L} E_{q_{l}}[Z]$.

(ii) $V^{-}(Z)=\min _{l \in L} E_{q_{l}}[Z]$.

(iii) If the payoffs from the claim $Z\left(\omega_{k}\right)$ are non-negative in all states, then these bounds are unaffected by the inability of agents to short sell securities.

This lemma is needed for several proofs in the Appendix as well as for models in $\S 4$ and $\S 5$.

\section{$3.2 \quad$ Agents}

We consider three types of agents in our model: investors, firms, and intermediaries. Investors are utility maximizers. Their decision problem is to construct a portfolio of primary securities (subject to budget constraints), so as to maximize expected utility. Investors can buy or sell primary

\footnotetext{
${ }^{4} \mathrm{~A}$ linear pricing measure is a probability measure that can take a value equal to zero in some states, whereas a risk neutral probability measure is strictly positive in all states. Thus, the set $\Theta$ is the interior of the convex set spanned by the set of independent linear pricing measures. The maximum dimension of this set equals the dimension of the solution set to a feasible finite-dimensional linear program, and thus, is finite. See Pliska (1997).
} 
securities, but cannot issue securities or short secondary securities. Firms own (real) assets and issue primary securities that are fully backed by the cash flows from these assets. Firms can also create new assets and sell claims against the cash-flows from these assets to intermediaries. ${ }^{5}$ They negotiate with intermediaries to get the highest possible value for their assets that is consistent with the prices prevailing in the financial market. Intermediaries facilitate transactions between firms and investors by repackaging the claims purchased from the firms and issuing secondary securities traded on the over-the-counter securities market.

We stipulate that the claims sold by firms to the intermediaries are fully backed by their asset cash flows, and the claims issued by the intermediaries are fully backed by the assets purchased from firms. We do not allow short sales of secondary securities or tranching of primary securities by intermediaries or investors. These assumptions have a few advantages in our analysis. First, since there are many reasons for the existence of intermediaries in practice, our assumptions enable us to isolate the roles of the three types of agents, and explicitly study the phenomenon of securitization through the intermediaries. Second, they enable us to avoid profits that can arise in an incomplete market from tranching existing securities. The value creation in our model is instead due to the cash flows of new projects. This matches the construction of standard asset-backed CDOs, as opposed to synthetic CDOs. With synthetic CDOs, there can be an opportunity to complete the market, leading to a new equilibrium, in which no specific conclusions about value creation can be obtained. In our model, secondary securities cannot be sold short, and we apply the "small firm" argument. Thus, the creation of secondary securities has a negligible effect on the prices of primary securities, and we avoid getting into the computation of a new general equilibrium. ${ }^{6}$ A third reason for these

\footnotetext{
${ }^{5}$ The new assets created by firms may also include assets that are already in place, but not yet securitized. For example, the loans made by a bank that are presently held on the asset side of its balance sheet may be candidates for securitization in a collateralized loan obligations structure. The bank would be a "firm" in the context of our model. In these cases, of course, the decision to acquire the assets in question has already been made and, to that extent, part of the analysis in this paper would not apply directly.

${ }^{6}$ In practice, borrowing and shorting secondary securities would require a liquid market for borrowing and lending in these securities, with modest transaction costs. Such a market might not exist particularly since the tranches are "bespoke," making it difficult to engage in short sales of illiquid securities.
} 
assumptions is to avoid transactions that permit default in some states, because that would lead to complex questions relating to bankruptcy and renegotiation, which are outside the purview of this paper.

We describe the decision making problems of the various agents as below:

Investors: We model investors by classifying them into a finite set of investor types denoted $I$. The utility derived by type $i$ investors is given by a von Neumann-Morgenstern function $U_{i}: \Re \times \Re \rightarrow \Re^{+}$. $U_{i}$ is assumed to be concave, strictly increasing, and bounded above. Investors maximize their expected utility subject to the constraint that consumption is non-negative in every state.

For each type $i$ investor in state $k$, let $e_{i}\left(\omega_{k}\right)$ denote the investor's endowment, $x_{i k}$ denote the consumption, and $P_{i}\left(\omega_{k}\right)$ be the subjective probability of state $k$. Also, let the portfolio of primary securities held by a type $i$ investor be denoted as the $N$-tuple of real numbers $\left(\alpha_{i 1}, \alpha_{i 2}, \ldots, \alpha_{i N}\right)$, where $\alpha_{i n}$ is the amount of security $n$ in the portfolio. The investor derives expected utility equal to $\sum_{k=0}^{K} P_{i}\left(\omega_{k}\right) U_{i}\left(x_{i 0}, x_{i k}\right)$. The type $i$ investor's decision problem can be written as

$$
\begin{aligned}
\max \left\{\sum_{k=0}^{K} P_{i}\left(\omega_{k}\right) U_{i}\left(x_{i 0}, x_{i k}\right):\right. & \\
x_{i k} & =e_{i}\left(\omega_{k}\right)+\sum_{n=1}^{N} \alpha_{i n} S_{n}\left(\omega_{k}\right), \forall k=1,2, \ldots, K \\
x_{i 0} & \left.=e_{i}\left(\omega_{0}\right)-\sum_{n=1}^{N} \alpha_{i n} p(n), \quad x_{i k} \geq 0, \forall k=0,1,2, \ldots, K .\right\}
\end{aligned}
$$

The first constraint equates the consumption in each state at time 1 with the cash flow provided by the portfolio and the endowment. The second specifies the budget constraint for investment in primary securities at time 0 . The third constraint specifies that the cash flow in each state at time 1 should be non-negative.

We denote the derivatives of $U_{i}$ with respect to $x_{i 0}$ and $x_{i k}, k \geq 1$, as $U_{i 1}$ and $U_{i 2}$, respectively. We shall assume, as customary, that the current period consumption is strictly bounded away from zero for investor types. It follows that, at optimality,

$$
\sum_{k=1}^{K} P_{i}\left(\omega_{k}\right) \frac{U_{i 2}\left(x_{i 0}, x_{i k}\right)}{\sum_{k=1}^{K} P_{i}\left(\omega_{k}\right) U_{i 1}\left(x_{i 0}, x_{i k}\right)} S_{n}\left(\omega_{k}\right) \leq p_{n} .
$$

Here, we obtain an inequality because of the restriction on consumption. The choice of the zero for the minimum consumption level is arbitrary, and could be changed to any other level of consumption that an investor type is loathe to fall below. The same effect is produced by short sales restrictions 
placed on individual investors. The inequality suggests that, in state $k$, type $i$ investors are willing to buy an infinitesimal amount of consumption at a price, $m_{i k}$ given by

$$
m_{i k}=P_{i}\left(\omega_{k}\right) \frac{U_{i 2}\left(x_{i 0}, x_{i k}\right)}{\sum_{k=1}^{K} P_{i}\left(\omega_{k}\right) U_{i 1}\left(x_{i 0}, x_{i k}\right)} .
$$

These values are called the (personal) state prices of investors. We require that each security is present in the optimal portfolio of at least one investor type. If no restrictions are placed on consumption levels or short sales of primary securities, then the state prices of each investor type will belong to the set $\Theta$.

Due to market incompleteness, the state prices for an unspanned state may differ amongst investor types. An investor of type $i$ is willing to buy not only consumption that is specific to state $k$, but also secondary securities issued by the intermediary if the price of the secondary security is below that given by valuing its state dependent cash flows, using the investor's state prices. We require at least two investor types in our model, otherwise the state prices of all investors will be identical and will give a single pricing measure even though the market is incomplete; see Cochrane (2001: Chapter 3) for a discussion of investors' state prices and risk-neutral pricing measures. We do not require the set of investor types to be fully specified or the intermediary to have access to all investor types.

Firms: Let $J$ denote the number of firms that wish to undertake investment projects at time 0 . Each firm maximizes the time 0 expected value of its investments. Firm $j$ can create an asset $X_{j}$ that is unique to it. The asset provides a positive cash flow of $X_{j}\left(\omega_{k}\right)$ in each state $k$, at time $t=1$. The firm can sell claims issued against $X_{j}$ to the intermediary. Recall that we require that claims issued against $X_{j}$ should be fully backed by $X_{j}$; in other words, the sum promised should not exceed the cash flow from $X_{j}$ in any state of nature. We assume that firm $j$ has a reservation price $r_{j}$ on $X_{j}$. The reservation price is exogenous. It includes financial, physical, and transaction costs incurred at time 0 , such as due to use of labor inputs for implementing the new project. It could also include opportunity costs of the key decision-makers of the firm that are required to create the asset. The firm invests in the asset if the net present value, determined by subtracting its reservation price from the selling price of future cash flows offered by the intermediary, is positive. 
Note that, in incomplete markets, the firm's objective is unclear because it is difficult to conceptualize unanimity of shareholders in valuing future cash flows. ${ }^{7}$ Our use of securitization resolves this problem because the price offered by the intermediary for the cash flows from the asset is paid at time 0 .

We assume that the total cash flow available from this set of firms in any state $k, \sum_{j=1}^{J} X_{j}\left(\omega_{k}\right)$, is small relative to the size of the economy. Each firm, therefore, behaves as a price-taker in the securities market. However, when the asset cannot be priced precisely, it negotiates with the intermediary for obtaining the highest possible price for securitization of the asset. In the rest of this paper, we use $X_{j}$ to refer to both the $j$-th asset and the cash flows from the $j$-th asset.

Intermediaries: Intermediaries are agents who have knowledge about the firms' and investors' asset requirements. Such knowledge is different from receiving a private signal regarding the future outcome. Hence, intermediaries have no superior information about future cash flows, relative to other agents in the economy. The intermediaries purchase assets from firms and repackage them to sell to investors. They seek to exploit price enhancement through securitization operations that increase the spanning of available securities. They use this superior ability to negotiate with the firms for the prices of their assets. They use the knowledge about the investors' preferences to create new claims and price them correctly. An important aspect of the model is that intermediaries act fairly by paying the same price for the same asset, independent of which firm is selling it to the pool, and charging the same price for the same product even though it is sold to different customers. The rationale for these fairness requirements is the possibility of entry and competition from other intermediaries. However, we do not explicitly model competition amongst intermediaries beyond imposing the fairness requirements and the participation constraints by firms that are discussed in the next section. Hence, in what follows, we consider the securitization problem from the viewpoint of a single intermediary.

The intermediary purchases claims from firms, pools them, and packages them into different

\footnotetext{
${ }^{7}$ See Magill and Quinzii (2002: Chapter 6). The project is new and is not included in the stock price of the firm. Its value will further depend on the type of financing and the benefits of pooling and tranching, which we seek to determine.
} 
tranches, and sells them as collateralized secondary securities. Pooling is defined as combining the cash flows from claims issued by different firms in a proportion determined by the intermediary. We do not restrict the intermediary to purchasing only all or none of a firm's cash flows. Instead, it can purchase fractions (between 0 and 1 ) of the available assets. Our results show conditions in which different types of pooling solutions are obtained. Tranching is defined as splitting the pooled asset into sub-portfolios to be sold to different groups of investors, with the constraint that the sub-portfolios be fully collateralized, i.e., fully backed by the claims purchased from the firms. We assume that the intermediary can sell secondary securities to investors in a subset of the investor classes, which is denoted as $I_{1} \subset I$.

Securitization naturally leads to the problem of moral hazard since firms may not have the incentive to service the cash flows that they have sold to the intermediary. This issue is addressed in the literature on information asymmetry, such as in DeMarzo (2005). The same results apply to our model as well, for example, if the firm and/or the intermediary retain an equity tranche themselves.

\section{Value of Pooling}

We attribute the beneficial role played by the intermediary to two factors: the value enhancement provided by pooling alone, and the value provided by tranching. This section considers the former. We analyze the problem of pooling the cash flows of some or all projects in the available set and valuing the pooled asset by replicating its cash flows in the securities market. We use the lower bound, $V^{-}(\cdot)$, as a measure of value, and thus, compute the lowest price at which the pooled asset can be sold without presenting opportunities for arbitrage. There are several reasons to take the minimum value representation, $V^{-}(\cdot)$, as a measure of value: First, it is the price at which the claim can be sold for sure in the market without assuming any knowledge about investors' preferences and state prices. Second, using $V^{-}(\cdot)$ minimizes the problem of adverse selection since the individual valuations cannot do worse than the minimum even with adverse selection (MasColell et al. 1995:p.436). Third, $V^{-}(\cdot)$ is a transparent measure of value since it is consistent with 
the prices of primary (traded) securities and can be computed by all agents in the market using knowledge of prices of primary securities alone. Fourth, the value of the marketable portion of the asset pool is unambiguous and the choice of $V^{-}(\cdot)$ only affects the valuation of cash flows outside the span of the market. Moreover, the conditions under which pooling can create value do not depend on the use of $V^{-}(\cdot)$. Of course, a price higher than $V^{-}(\cdot)$ is possible when preferences and state prices are known at least for a subset of investors. In $\S 6$, we address how such higher value can be realized by solving the tranching problem.

Consider any given firm $j$. If $r_{j} \leq V^{-}\left(X_{j}\right)$, then clearly, firm $j$ can profitably invest in asset $X_{j}$, even without pooling. If $r_{j} \geq V^{+}\left(X_{j}\right)$, then it does not make sense for the firm to invest in the asset $X_{j}$. The interesting case is the one where $V^{+}\left(X_{j}\right) \geq r_{j} \geq V^{-}\left(X_{j}\right)$, because, in this case, the basis for the decision to invest in $X_{j}$ is ambiguous. To define the value of pooling, suppose that a pooled asset is created with cash flows $X\left(\omega_{k}\right)=\sum_{j} X_{j}\left(\omega_{k}\right)$ for all $k$. Clearly, $V^{-}(X) \geq \sum_{j} V^{-}\left(X_{j}\right){ }^{8}$ However, it is important to note that this inequality is not sufficient to determine the value of pooling. We still need to consider the reservation prices of firms to determine if pooling reduces the ambiguity regarding investment in assets. We postulate that there is value to pooling in this latter sense if there is a linear combination of assets with weight $0 \leq \alpha_{j} \leq 1$ for asset $j$ such that $V^{-}\left(\sum_{j}\left(\alpha_{j} X_{j}\right)\right) \geq \sum_{j}\left(\alpha_{j} r_{j}\right)$ and $\alpha_{j}>0$ for at least one firm $j$ for which $V^{-}\left(X_{j}\right)<r_{j}$. Another way of defining this type of value creation is that the set of projects fully or partially financed from payments derived from the asset pool is larger than the set of such projects prior to pooling. Furthermore, in our formulation, firms need not behave altruistically in creating the asset pool; therefore, as an additional condition for value creation, we require that firms should have an incentive to pool their assets only when they cannot benefit, individually or severally, from breaking away from the pool.

Theorem 1 shows the necessary condition for creating value through pooling. The rest of the section determines sufficient conditions for value creation.

\footnotetext{
${ }^{8}$ The left hand side is given by minimizing the sum of the cash flows from all assets over the set of probability measures, whereas the right hand side is the sum of the minimum of each individual cash flow. The minimum of the sum is always larger than or equal to the sum of minimums.
} 
Theorem 1. (i) If there is a $q \in \Theta$ such that $r_{j} \geq E_{q}\left[X_{j}\right] \forall j$, then value cannot be created by pooling the $X_{j}$ 's.

(ii) Conversely, if there is no $q \in \Theta$ such that $r_{j} \geq E_{q}\left[X_{j}\right] \forall j$, then value can be created by pooling the $X_{j}$ 's.

The first part of the theorem states that if the reservation price for each asset is higher than its value under a common pricing measure, then additional value cannot be created through pooling. Conversely, if the condition in part (i) of the theorem fails to hold, then part (ii) states the positive part of the result, that is, there exists a vector of weights $\left(\alpha_{j}\right)$ such that pooling leads to value enhancement. However, $\alpha_{j}$ need not be unique. For ease of presentation, we initially assume that the condition in Theorem 1(ii) holds for $\alpha_{j}=1$ for all $j$, i.e., there is value in pooling all the cash flows from all firms. We first present all the results under this assumption. Then, we generalize them to the case when the condition in Theorem 1(ii) holds, but necessarily with $0<\alpha_{j}<1$ to create value by pooling.

As mentioned before, even when the value of the pooled asset exceeds the sum of the reservation prices, some firms might be unwilling to participate in the asset pool. This could happen, for example, if one firm has a very high reservation price, so that the remaining firms are better off keeping it out of the pool. This naturally leads to the following set of questions: Can we characterize reservation prices such that there is an incentive for firms to pool their assets? Can a fair price be set for each $X_{j}$ ? How many asset pools would be created and what would be the composition of these asset pools? The remainder of this section answers these questions.

We stipulate that firms will participate in the pool only if they cannot do better by forming sub-coalitions amongst themselves. We, therefore, model the firms' participation problem as a cooperative game, $\mathcal{G}$ (Owen 1995). Let $J_{w}$ denote a subset of the set of all firms, $J$, wherein each firm $j$ contributes a fraction $w_{j} \in[0,1]$ of its cash flows with proportional reservation price $w_{j} r_{j}$. Let $J_{w}^{c}=J-J_{w}$ denote the complement of $J_{w}$, wherein the contribution of each firm $j$ is $\left(1-w_{j}\right) X_{j}$ and reservation price is $\left(1-w_{j}\right) r_{j}$. Also let $X\left(J_{w}\right)=\sum_{j \in J_{w}} w_{j} X_{j}$. We consider the cooperative game in which the value of each coalition, $V\left(J_{w}\right)$, is defined as $V^{-}\left(X\left(J_{w}\right)\right)$. In this game, we allow coalition formation with fractional assets being pooled together. Following 
standard terminology for cooperative games, we say that there is a solution to this game, i.e., its core is non-empty, if the grand coalition of all firms cannot be blocked. The theorem below provides sufficient conditions for the core of the game to be non-empty, as well as conditions that guarantee that payments can be made to the firms to cover their reservation prices. These results can be related to the arguments for pooling presented in the context of information asymmetry by Leland and Pyle (1977), Subrahmanyam (1991), and especially DeMarzo (2005). In these papers, the benefits from pooling arise from a reduction in adverse selection costs and improvement in liquidity due to pooling. In our case, the benefits from pooling arise from the exploitation of arbitrage that occurs even after compensating the particular firms for their reservation prices. Both arguments complement each other in explaining real world applications of pooling.

Theorem 2. (i) If $r_{j} \leq V^{-}\left(X_{j}\right)$ for all $j$, then the core of game $\mathcal{G}$ is not empty.

(ii) There is a solution in the core to $\mathcal{G}$ such that the payments to all firms exceed their reservation prices if and only if for every subset $J_{w}$ of $J$, we have $V(J) \geq \max \left(V\left(J_{w}\right), \sum_{j \in J_{w}} w_{j} r_{j}\right)+$ $\max \left(V\left(J_{w}^{c}\right), \sum_{j \in J_{w}^{c}}\left(1-w_{j}\right) r_{j}\right)$.

The first part of this theorem follows from a proof in Owen (1975). In the context of securitization, we infer from this result that even when the reservation prices are so small that projects can be financed without pooling, there may still be incentive to create the pool and share the benefits. When the reservation prices are larger, Theorem 2(ii) states that the necessary condition for the payments to firms to support the core is also sufficient to guarantee its existence. The necessary part of Theorem 2(ii) is immediate, because under every solution in the core, each coalition $J_{w}$ should get at least $\max \left(V\left(J_{w}\right), \sum_{j \in J_{w}} w_{j} r_{j}\right)$. If this condition does not hold, then either some coalition does not get its value (and can do better on its own) or the payment to the firms in some coalition cannot cover the sum of the reservation prices. The sufficiency part uses a different argument and is new. It shows that when the condition holds for all possible $J_{w}$, all firms participate and all projects are financed in full. Notice that we do not need to verify the condition in Theorem 2(ii) for all possible partitions of $J$. Instead, verifying the condition for partitions of size two is sufficient. 
Notice also that the inequalities in Theorem 2(ii) must be tested not only for partitions with $w_{j}=0$ or 1 for all $j$, but also those with fractional values of $w_{j}$, i.e., partitions where a firm belongs to two or more subsets and divides its cash flows between them. This continuum of partitions makes it virtually impossible to use Theorem 2(ii) directly in practice to determine the composition of the asset pool. However, this task can be avoided. We show that there is a simple condition that is necessary and sufficient for all the inequalities in 2(ii) to be satisfied. Thus, under this condition, the cash flows from each asset $X_{j}$ are included fully in the pool and the core of the cooperative game is not empty.

Theorem 3. Let $q \in \Theta$ be a pricing measure under which $\sum_{j} E_{q}\left[X_{j}\right]=V^{-}\left(\sum_{j} X_{j}\right)$. If $E_{q}\left[X_{j}\right] \geq r_{j}$ for all $j$ and some such $q$, then the sufficiency conditions in Theorem 2(ii) are satisfied. The converse is also true.

We remark on the symmetry between this result and Theorem 1(i). The result in Theorem 1(i) is that if, under a common pricing measure, each asset's value is less than its reservation price then there is no value in pooling. The new result is that if, under a pricing measure that minimizes the value of the asset pool, the value of each asset equals or exceeds its reservation price then value can be created unambiguously by pooling all assets. Value is also created (in the sense that additional projects are undertaken) if some project whose value was below the reservation price gets financed through the pooling effect.

While Theorems 2 and 3 show that there exist payment schemes such that firms are willing to participate in the game $\mathcal{G}$, we need to address the question of actually determining the payment scheme to the firms, which we now turn to. It is possible to show that there could be many such schemes, but we also require the scheme to be "fair." It is difficult to work with the concept of "fairness" in complete generality. However, a case can be made that if all firms are paid the same price for a unit cash flow in state $k$, then the scheme is fair. We therefore restrict ourselves to payments determined using a linear pricing measure. The following corollary complements the results so far by using the sufficient condition of Theorem 3 to construct a linear pricing scheme.

Corollary 1. If a pricing measure $q_{p}$ exists that is either an extreme point of the set of risk 
neutral probability measures, or a convex combination of such extreme points, such that $\sum_{j} E_{q_{p}} X_{j}=$ $V^{-}\left(\sum_{j} X_{j}\right)$, and the reservation prices satisfy $r_{j} \leq E_{q_{p}} X_{j}$, then the grand coalition of all firms can be sustained when firm $j$ is paid $E_{q_{p}} X_{j}$.

Corollary 1 implies that pooling creates value from two perspectives. The first is given by the change in the pricing measure that is necessary to value the assets correctly. Suppose that firm $j$ cannot decide whether to invest in the project based on the minimum valuation, i.e., $r_{j} \geq V^{-}\left[X_{j}\right]=$ $E_{q_{j}}\left[X_{j}\right]$, where $q_{j}$ is the pricing measure that gives the lower bound on the value of firm $j$ 's asset, and depends on the cash flow of the asset. From Corollary 1, the measure $q_{p}$ to determine the value when the project is considered to be part of the asset pool depends on the cash flow of the entire asset pool. The use of this measure yields a higher value for each project. Thus, firm $j$ surely gains when the reservation price lies within these two bounds. The second perspective is that more projects are financed than without pooling. When we are restricted to compensate firms using the same pricing measure, we are assured that the gain from pooling can be used to induce all firms to participate when $r_{j} \leq E_{q_{p}} X_{j}$. There are other interesting aspects to the corollary. The pricing scheme is fair because it uses the same pricing formula for each firm. It also prices the traded securities correctly. Thus, firms can use a market benchmark to assure themselves that the intermediary is fair.

The above results characterize the situations in which all firms participate and contribute all their assets. A critical condition for full participation by firms is $E_{q_{p}}\left(X_{j}\right) \geq r_{j}$ for all $j$ and $q_{p}$ as defined in Corollary 1. However, note that according to Theorem 1, there are situations where there is value in pooling only fractions of cash flows of the firms. Further, the value of $\left\{\alpha_{j}\right\}$ for each firm $j$ that provides value in pooling may not be unique. The following corollary highlights one such solution. We show that there exists an optimal value of $\left\{\alpha_{j}\right\}$ for each $j$, denoted $\left\{\alpha_{j}^{*}\right\}$, that maximizes the value of the pool. Further, if we treat $\alpha_{j}^{*} X_{j}$ 's as the constituent assets instead of $X_{j}$ 's, then Theorems 2 and 3 still apply to this asset pool.

Corollary 2. If the condition in Theorem 1(ii) holds, then the value of pooling is maximized by solving the linear program: $\max V^{-}\left(\sum_{j} \alpha_{j}\left(X_{j}\right)\right)-\sum_{j} \alpha_{j} r_{j}$, subject to $0 \leq \alpha_{j} \leq 1, \forall j$. An optimal 
solution to this linear program, $\alpha_{j}^{*}$ for all $j$, is in the core of $\mathcal{G}$. The assets of firms whose value exceeds their respective reservation price will be included fully in this asset pool. Moreover, the cash flows left over, $\left\{\left(1-\alpha_{j}^{*}\right) X_{j}\right\}$, do not provide any value in pooling.

Corollary 2 is consistent with Theorem 3 , because if $E_{q_{p}}\left[X_{j}\right] \geq r_{j}$ for all $j$, then it can be shown that setting $\alpha_{j}^{*}=1$ for all $j$ gives an optimal solution to the linear program in Corollary 2. When some $\alpha_{j}^{*}$ is fractional, it is difficult to construct a fair payment scheme, because it simultaneously requires limiting the fraction of assets purchased at that price. Moreover, value creation from both perspectives is possible, but, it is difficult to separate out the benefits given by the formation of the pool from those due to securitization.

In summary, this section characterizes the value in pooling. Theorem 1(i) and (ii) show the conditions under which there is no value in pooling, and those under which there is such value. In the latter case, Theorems 2 and 3 and Corollary 2 together show that there is a maximal coalition that can be sustained. This coalition achieves the maximum value of pooling. It includes all the assets when the condition in Theorem 3 holds, and fractional assets otherwise. Corollary 1 guarantees the existence of a linear payment scheme for this coalition. The assets not included in this coalition cannot be reconstituted as a separate value enhancing pool. The value creation comes about due to synergies in cash flows amongst assets as viewed from the market prices of primary securities. The value-maximizing behavior of a firm or a subset of firms does not impede the correct (value maximizing) pool from forming. Thus, intermediation and pooling are predictable outcomes, without reference to the preferences of individual agents.

\section{$5 \quad$ Value of Pooling and Tranching}

In this section, we assume that, in addition to tranches that are replicas of primary securities already traded in the securities market, the intermediary can also create and sell new securities, fully backed by the pool of assets, directly to investors. We call the former marketable tranches, and the latter non-marketable tranches or secondary securities. If the sum of the prices of marketable tranches (which are unique) and the prices of non-marketable tranche (which are obtained by selling 
each tranche at investor-specific state prices $m_{i k}$ ) exceeds the value obtained by pure pooling, then we shall conclude that tranching provides value enhancement beyond pure pooling.

In general, the cash flows from a given asset pool, say, $\sum_{j} w_{j} X_{j}$ can be split into several tranches, and each tranche offered to every investor type. Recall that $m_{i k}$ denotes the state price of investor type $i$, for a unit consumption in state $k$. Let

$$
m_{k}^{*}=\max _{i \in I_{1}} m_{i k}
$$

where $I_{1}$ is the subset of investor classes to whom the intermediary can sell secondary securities. It is clear that the cash flow in state $k$ should be sold to the investor type that values it the most. Therefore, the maximum price that the intermediary expects from a tranche sold in state $k$ is $m_{k}^{*}$. Thus, we do not use $V^{-}(\cdot)$ as the valuation criterion. Instead, the set of investors about whom the intermediary has information provides the valuation criterion. We first derive the optimal tranching solution for a given asset pool. Later on, we examine whether the additional ability to tranche the pool, in turn, influences the choice of the asset pool in the first place.

Given the asset pool, we formulate the problem of designing the optimal tranches that maximize the value of the asset pool as follows:

$$
V^{T}(J)=\max \sum_{k} m_{k}^{*}\left(Y_{k}-l_{k}\right)+\sum_{n} p_{n} \beta_{n}
$$

such that

$$
\begin{array}{r}
Y_{k}+\sum_{n} \beta_{n} S_{n}\left(\omega_{k}\right) \leq \sum_{j \in J} w_{j} X_{j}\left(\omega_{k}\right) \text { for all } k \\
\sum_{n} \beta_{n} S_{n}\left(\omega_{k}\right)+l_{k} \geq 0, \text { for all } k \\
Y_{k}, l_{k} \geq 0, \quad \beta_{n} \text { unrestricted for all } k, n .
\end{array}
$$

Here, $\beta_{n}$ is the weight of primary security $n$ in the marketable tranche, $l_{k}$ equals the amount of negative cash flow from the marketable tranche in state $k$, and $Y_{k}-l_{k}$ is the cash flow of the non-marketable tranche in state $k$. The objective is to maximize the combined value of the tranches. The objective function removes the cash flow, $l_{k}$, from the intermediary's profits to prevent the intermediary from exploiting any arbitrage opportunities available in the market by 
tranching primary securities. Constraints (3)-(4) specify that the tranches should be fully backed only by the asset pool. In constraint (3), we state that the sum of cash flows of the tranches must be less than the cash flow of the asset pool in each state $k$. In constraint (4), we preclude the possibility that the intermediary may short primary securities and use the proceeds to create a new non-marketable tranche. This formulation captures the constraint placed on SPV's that any security issued by an SPV should be backed by the asset pool and not from any market operation. ${ }^{9}$ Finally, the non-negativity constraints on $Y_{k}$ in (5) specify that short sales of secondary securities are not allowed, i.e., the non-marketable tranche should only have positive components. This is justified by recalling that consumption should be non-negative in all states.

The optimal tranching results are based on the dual of (2)-(5) formulated as below:

$$
D^{T}(J)=\min \sum_{k} \lambda_{k} \sum_{j \in J} w_{j} X_{j}\left(\omega_{k}\right)
$$

such that

$$
\begin{aligned}
\lambda_{k} & \geq m_{k}^{*} \text { for all } k \\
\delta_{k} & \leq m_{k}^{*} \text { for all } k \\
\sum_{k}\left(\lambda_{k}-\delta_{k}\right) S_{n}\left(\omega_{k}\right) & =p_{n} \text { for all } n \\
\lambda_{k}, \delta_{k} & \geq 0, \text { for all } k .
\end{aligned}
$$

Here, $\lambda_{k}$ and $\delta_{k}$ are the dual variables corresponding to constraints (3) and (4), respectively, of the primal problem. The dual program's objective function states that $\lambda_{k}$ are the state prices that determine the optimal value of the asset pool realized by tranching. Constraint (9) implies that $\left(\lambda_{1}-\delta_{1}, \ldots, \lambda_{K}-\delta_{K}\right) \in \Theta$ because this vector is non-negative and prices all primary securities correctly. Thus, $\delta_{k}$ measure the distance of the state prices obtained by allowing tranching from the set $\Theta$. Let $\Omega^{a}$ be the set of states in which $\delta_{k}>0$ in the optimal dual solution.

The following lemma formally states that the optimal solution of the dual problem lies in a bounded region, and therefore, by implication, the primal problem does not lead to infinite

\footnotetext{
${ }^{9} \mathrm{~A}$ less stringent constraint, allowing for partial use of the proceeds of the short sales of primary securities to augment the pool, would expand the feasible set. However, this would only introduce a somewhat different shadow price, but would be qualitatively similar to the rest of the analysis presented here.
} 
arbitrage (see the Fundamental Duality Theorem, Murty (1983:p.192)). The lemma shows that we preclude the intermediary from issuing new secondary securities by short selling primary securities, and thus, taking advantage of arbitrage in an obvious way. For the purposes of this lemma, let $S_{D^{T}}$ be the set of feasible solutions to the dual program, and $\mathcal{B}$ be a bounded polyhedral convex set defined as $\prod_{k}\left[0, \max \left(1, \max _{k} m_{k}^{*}\right)\right] \times\left[0, \max \left(1, \max _{k} m_{k}^{*}\right)\right]$.

Lemma 2. The optimal solution to the dual problem is obtained by computing the value of the asset pool at each extreme point of $\mathcal{B} \cap S_{D^{T}}$ and taking the minimum value as the solution.

From this lemma, the primal problem $V^{T}(J)$ has a finite optimal solution. Therefore, the tranching solution exploits only those arbitrage opportunities in the securities market that are available to the intermediary due to the access to the asset pool and the subset of investors $I_{1}$. It does not include possible arbitrage opportunities that may exist in the market due to discrepancies between the prices of primary securities in the market and the secondary securities demanded by investors. ${ }^{10}$ The following theorem defines such opportunities and shows that they are completely characterized by the set $\Omega^{a}$.

Theorem 4. (i) If there exists a non-negative contingent claim $Z$ such that $\sum_{k^{\prime}} m_{k^{\prime}}^{*} Z\left(\omega_{k}^{\prime}\right)>$ $V^{+}(Z)$, then there is no feasible solution to the dual in $\Theta$. In particular, $\Omega^{a}$ is not empty.

(ii) If there exists a non-negative contingent claim $Z$ such that $\sum_{k^{\prime}} m_{k^{\prime}}^{*} Z\left(\omega_{k}^{\prime}\right)>V^{+}(Z)$, then $Z$ is strictly positive in some state $k \in \Omega^{a}$.

(iii) If $\Omega^{a} \neq \emptyset$, then there exists a non-negative contingent claim $Z$ that is strictly positive in some state $(s) k \in \Omega^{a}$ and zero elsewhere, such that $\sum_{k^{\prime}} m_{k^{\prime}}^{*} Z\left(\omega_{k}^{\prime}\right)>V^{+}(Z)$.

(iv) If there exists a non-negative contingent claim $Z$ such that $\sum_{k^{\prime}} m_{k^{\prime}}^{*} Z\left(\omega_{k}^{\prime}\right)>V^{+}(Z)$, then there does not exist any $q \in \Theta$ such that $q_{k} \geq m_{k}^{*}$ for all $k$.

Theorem 4(i)-(ii) show that contingent claims that present arbitrage with the given subset of investors must have positive cash flows in one or more states in the set $\Omega^{a}$. The intermediary can short primary securities to create a contingent claim that pays off in these states and sell the

\footnotetext{
${ }^{10}$ This is in line with the argument of DeMarzo (2005) that incomplete markets may not explain the securitization of existing marketable assets.
} 
tranches to the subset of investors to realize an immediate profit. This is the consequence of the value to the investors exceeding $V^{+}(Z)$. Note that part (ii) also implies that if a claim does not have positive cash flows in any of the states in $\Omega^{a}$, then the upper bound on the price of the claim exceeds the value to the subset of investors. Theorem 4(iii) strengthens the role of the set $\Omega^{a}$. It states that if $\Omega^{a}$ is non-empty, then there is a non-negative contingent claim with cash flows in this set of states only, whose value to investors exceeds $V^{+}(Z)$. The last part of Theorem 4 is the dual characterization which is mathematically the most useful of the three. Using this result, we can now state the general structure of the secondary securities.

Let $Y_{k}^{*}, l_{k}^{*}$, and $\beta_{n}^{*}$ denote the optimal solution to the primal problem, and $\lambda_{k}^{*}$ and $\delta_{k}^{*}$ denote the optimal solution to the dual problem. We partition the optimal tranching solution into three parts that we denote as $T^{a}, T^{I}$ and $T^{m}$. Let $T_{k}^{a}=Y_{k}^{*}-l_{k}^{*}$ if $\delta_{k}^{*}>0$ and zero otherwise, let $T_{k}^{I}=Y_{k}^{*}-l_{k}^{*}-T_{k}^{a}$, and let $T_{k}^{m}=\sum_{n} \beta_{n} S_{n}\left(\omega_{k}\right)$. Here, $T^{m}$ is the marketable tranche, $T^{a}$ consists of the cash flows of the non-marketable tranche in states belonging to the set $\Omega^{a}$, and $T^{I}$ consists of the cash flows of the non-marketable tranche in the remaining states. We partition the nonmarketable tranche in this manner by applying the complementary slackness property (Murty 1983:p.197). By this property, $\delta_{k}^{*}>0$ implies that $l_{k}^{*}+\sum_{n} \beta_{n}^{*} S_{n}\left(\omega_{k}\right)=0$, which further implies that $Y_{k}^{*}-l_{k}^{*}=\sum_{j} w_{j} X_{j}\left(\omega_{k}\right)$, i.e., all the cash flows in state $k$ are sold as secondary securities. Thus, according to Theorem $4, T^{a}$ is based on exploiting the arbitrage opportunities in the securities market due to the ability to design and sell secondary securities to a subset of investors, while $T^{m}$ and $T^{I}$ are not based on the existence of arbitrage. $T^{a}$ is zero if there are no arbitrage opportunities available to the intermediary.

Note that the complementary slackness property also implies that the intermediary tranches all of the cash flows in the asset pool in the states belonging to the set $\Omega^{a}$ in the form of $T^{a}$. Indeed, we have $T_{a} \cdot T_{m}=0$ and $T_{a} \cdot T_{I}=0$. Thus, the optimal solution to the primal problem $V^{T}(J)$ is separable into one that corresponds to the tranches $T_{a}$ and another that corresponds to the rest. The value of $T^{a}$ is independent of changes in the cash flows of the asset pool in states $\Omega \backslash \Omega^{a}$, and likewise, the values of $T^{m}$ and $T^{I}$ are independent of the cash flows in states $\Omega^{a}$. To see this, define $\widehat{X}\left(\omega_{k}\right)=\sum_{j} w_{j} X_{j}\left(\omega_{k}\right)-T_{k}^{a}$ as the asset pool after tranching $T^{a}$. Set $\widehat{m}_{k}^{*}=0$ for the states where 
$\delta_{k}^{*}>0$, and $\widehat{m}_{k}^{*}=m_{k}^{*}$ otherwise. Let $\widehat{D}^{T}$ denote the new dual problem. Clearly, $\widehat{D}^{T}$ has a feasible solution in $\Theta$. Due to the fact that $T^{a}$ is orthogonal to $T^{m}$ and $T^{I}$, the optimal solution to $D^{T}$ is given by $T^{m}$ and $T^{I}$. Thus, the values of $T^{m}$ and $T^{I}$ are independent of the value of $T^{a}$. Therefore, the asset pool decomposes into an 'arbitrage part', a marketable part and a residual part. In the terminology of the securitization industry, roughly speaking, the first component can be referred to as a "bespoke" tranche, the second one as a super-senior tranche, and the last one as the equity tranche.

We can now specify the complete structure of the optimal tranching solution for a given asset pool as stated in the theorem below. This theorem uses the results of Theorem 4 to show the conditions under which the different tranches come about.

Theorem 5. The optimal solution to the tranching problem is represented by $\left(T^{a}, T^{m}, T^{I}\right)$ as defined above. Further,

(i) If there exists $q \in \Theta$ such that $q_{k} \geq m_{k}^{*}$ for all $k$, then $T^{a} \equiv 0$.

(ii) If there exists $q \in \Theta$ such that $q_{k} \leq m_{k}^{*}$ for all $k$ and $q_{k}<m_{k}^{*}$ for some $k$, then there exists an optimal tranching solution in which $T^{m}=T^{I} \equiv 0$.

(iii) Otherwise all three types of tranches may occur in the optimal solution.

We note from Theorem 5 that the differences among the three types of solutions to the tranching problem do not depend on the cash flows in the asset pool, but only on the set $\Theta$ and the state prices $m_{k}^{*}$. Thus, an intermediary can verify the results in Theorems $4-5$ without knowing the cash flows in the asset pool or the willingness of individual firms to participate in the asset pool. Further, the tranches in $T^{m}$ might be bought by a different set of investors than $I_{1}$, which is the set of investors that buys tranches $T^{a}$ and $T^{I}$.

Theorem 5 also clearly delineates the incremental value realized by tranching the given asset pool $\sum_{j} w_{j} X_{j}$. In case (i), $\lambda^{*} \in \Theta$, and thus, the optimal solution to the dual problem lies inside the price bounds $V^{-}\left(\sum_{j} w_{j} X_{j}\right)$ and $V^{+}\left(\sum_{j} w_{j} X_{j}\right)$. By the constraints of the dual problem, this solution is obtained in the set $\Theta \bigcap\left\{\left(\lambda_{1}, \ldots, \lambda_{K}\right): \lambda_{k} \geq m_{k}^{*}\right.$ for all $\left.k\right\}$. Since this is a subset of $\Theta$, pooling and tranching provides incremental value beyond $V^{-}\left(\sum_{j} w_{j} X_{j}\right)$. In case (ii), the optimal 
solution is given by $E_{m^{*}}\left[T^{a}\right]$, which is greater than $V^{+}\left(T^{a}\right)$. In case (iii), the value of tranches $T^{m}$ and $T^{I}$ is as in case (i) and the value of tranche $T^{a}$ is as in case (ii). Due to the orthogonality of $T^{a}$ with $T^{m}$ and $T^{I}$, the total value is equal to the sum of these two components. Thus, the value from pooling and tranching is higher than $V^{-}\left(\sum_{j} w_{j} X_{j}\right)$.

Thus far in this section, we have presented results for a given asset pool. We now examine the implications of tranching on the formation of the asset pool. First, note that the optimal value created through pooling and tranching will always be at least as large as that from pure pooling. However, the asset pool that maximizes the value from pooling and tranching may not be the same as that which maximizes the value from pure pooling. This naturally gives rise to questions whether the optimal asset pool under pooling and tranching will be larger than that under pure pooling, and whether it will include all the assets in the latter pool. We examine these questions for each case in Theorem 5 .

In case (i), all results of $\S 4$ apply if attention is restricted to the smaller set of pricing measures $\Theta^{T}=\left\{q: q_{k} \geq m_{k}^{*}, q \in \Theta\right\}$. Thus, using the inferences in $\S 4$, the asset pool may consist of cash flows from the individual firms in fractions or in full. Further, the mix of projects that get financed may change compared to the solution in $\S 4$, however, the total value of the projects financed will always increase. Note that, in this case, the minimum value actually corresponds to selling the assets to the restricted set of investors in a particular way with the unsold part having no value to those investors. In case (ii), the optimal solution is linear in the cash flows $X\left(\omega_{k}\right)$. Thus, the solution degenerates into a pure tranching solution and there is value from tranching, but there may not be value from pooling. The decision for each firm to go through the intermediary is made separately based on whether $E_{m^{*}}\left[X_{j}\right] \geq r_{j}$ or not. Thus, each firm either participates in the pool in full or not at all. The mix of projects financed may again change compared to $\S 4$, however, there will be no fractional pooling in this case. In case (iii), the pooling and tranching solution lies outside the set $\Theta$. The remaining implications in this case are the same as in case (i). Thus, we obtain the counter-intuitive conclusion that the optimal asset pool in pooling and tranching may not include all the assets included in pure pooling, and may in fact be smaller than the latter. 


\section{Numerical Example}

We illustrate the insights from our model, focusing on the role of reservation prices of potential new assets in determining the optimal pooling and tranching solution, its sustainability, and its effect on real investment. The example of a real investment decision we consider is an inventory decision with random demand.

Suppose that there are four states of nature at time 1 denoted $\Omega=\left\{\omega_{1}, \ldots, \omega_{4}\right\}$, and there are two primary securities in the financial market with payoffs $S_{1}=(1,1,1,1)$ and $S_{2}=(1,0,0.5,1.5)$ at time 1 and prices $p_{1}=p_{2}=1$ at time 0 . The set of risk neutral pricing measures over $\Omega$ is $\Theta=\{(x+3 y, x-y, 0.5-2 x, 0.5-2 y)\} \bigcap[0,1]^{4}$ with two degrees of freedom denoted $x$ and $y$. The set $\Theta$ is spanned by three linear pricing measures, $Q_{1}=(0,1 / 3,0,2 / 3), Q_{2}=(1,0,0,0)$, and $Q_{3}=(0,0,1 / 2,1 / 2) . Q_{1}$ corresponds to $x=1 / 4, y=-1 / 12, Q_{2}$ corresponds to $x=1 / 4, y=1 / 4$ and $Q_{3}$ corresponds to $x=0, y=0$.

Consider two investor types in this market with identical preferences given by $U_{i}\left(c_{1}, c_{2}\right)=$ $c_{0}-e^{-5 c_{1}}$ for $i=1,2$, where $c_{0}$ denotes consumption at time 0 and $c_{1}$ denotes consumption at time 1. The investor types differ in their endowments in different states, being given as $e_{1}=$ $(10,0.4,1.6,1,0)$ and $e_{2}=(10,0.5,0,0,0.1)$. Such differences in endowments can occur due to differences in demographics, geographical location, or lifecycle. Both investor types have the same subjective probabilities for the four states given as $P=(0.4,0.1,0.15,0.35)$. Each investor solves the decision problem specified in $§ 3.2$ in order to maximize total expected utility. Table 1 shows the equilibrium investments and state prices of the investor types with and without constraints on the short sale of primary securities by investors.

Suppose that there are three firms facing inventory decisions at time 0 as follows. Firm 1 has random demand $D_{1}=(1,1,0,0)$ at time 1 , firm 2 has demand $D_{2}=(0,0,1,0)$, and firm 3 has demand $D_{3}=(0,0,0,1)$. The selling price is normalized to 1 and the per unit procurement prices are $r_{1}, r_{2}$ and $r_{3}$, respectively. We will consider different values of these prices, and thus, $r_{1}, r_{2}$ and $r_{3}$ will be specified later. The firms' decisions are the amounts of inventory of the three products to procure at time 0 in order to maximize the respective value to shareholders. If firm $j$ buys inventory 
Table 1: Equilibrium consumption, investments, and state prices for the two investor types before introduction of secondary securities

\begin{tabular}{|c|c|c|c|c|c|}
\hline \multirow{2}{*}{$\begin{array}{l}\text { Investor } \\
\text { type }\end{array}$} & \multirow{2}{*}{$\begin{array}{c}\text { Equilibrium } \\
\text { demand } \\
\text { for equity } \\
\left(S_{1}, S_{2}\right)\end{array}$} & \multicolumn{2}{|c|}{ Consumptions } & \multirow{2}{*}{$\begin{array}{c}\text { State prices } \\
m_{i k}\end{array}$} & \multirow{2}{*}{$\begin{array}{c}\text { Expectec } \\
\text { Utility }\end{array}$} \\
\hline & & $c_{0}$ & $c_{1}$ & & \\
\hline \multicolumn{6}{|c|}{ With short sales constraints: } \\
\hline 1 & $(0.1474,0)$ & 9.8526 & $\begin{array}{c}(0.5474,1.6, \\
1.0737,0.2212)\end{array}$ & $\begin{array}{l}(0.1295,0.0002, \\
0.0035,0.5792)\end{array}$ & 9.7100 \\
\hline 2 & $(0,0.1813)$ & 9.8187 & $\begin{array}{c}(0.6813,0.1813, \\
0.1813,0.2813)\end{array}$ & $\begin{array}{l}(0.0663,0.2020 \\
0.3030,0.4288)\end{array}$ & 9.6187 \\
\hline \multicolumn{6}{|c|}{ Without short sales constraints: } \\
\hline 1 & $(1.0414,-1.1804)$ & 10.1390 & $\begin{array}{c}(0.2610,0.4196, \\
0.3403,0.3817)\end{array}$ & $\begin{array}{c}(0.5423,0.0614 \\
0.1368,0.2595)\end{array}$ & 9.9390 \\
\hline 2 & $(-0.0785,0.2544)$ & 9.8241 & $\begin{array}{c}(0.6759,0.2544, \\
0.2152,0.2366)\end{array}$ & $\begin{array}{l}(0.0681,0.1401, \\
0.2558,0.5360)\end{array}$ & 9.6241 \\
\hline
\end{tabular}

$\alpha_{j}$, then the procurement price is $\alpha_{j} r_{j}$ and the cash flow at time 1 is $X_{j}=\min \left\{\alpha_{j} e_{4}, D_{j}\right\}$, where $e_{4}=(1,1,1,1)$. For example, if $\alpha_{1}=0.5$, then $X_{1}=(0.5,0.5,0,0)$. These cash flows are unique to the firms due to uniqueness of their products, customer base, or supply chain network.

This setting maps to our model since $X_{j}$ can be interpreted as cash flows from the firms' real investment decisions with reservation prices $\alpha_{j} r_{j}$. This is a simple example since $D_{1}+D_{2}+D_{3}$ gives us the risk-free bond. Even so, it suffices to illustrate the values of reservation prices that yield different pooled assets and different inventory decisions. We see that $X_{j}$ are not spanned by $\Theta$ for any positive value of inventory, and thus, do not have unique prices in this market. The price bounds on $X_{1}$ are $\left[V^{-}\left(X_{1}\right), V^{+}\left(X_{1}\right)\right]=\left[0, \alpha_{1}\right]$, and on $X_{2}$ and $X_{3}$ are $\left[0, \alpha_{2} / 2\right]$ and $\left[0,2 \alpha_{3} / 3\right]$, respectively. Therefore, if each firm considers its decision in isolation and use the lower bound $V^{-}\left(X_{j}\right)$ as the measure of value, then its optimal inventory will be zero.

Before describing our solution, it is instructive to apply the CAPM to this example, similar to Anvari (1987) for the case of complete markets. In the appendix, we present the valuations and optimal inventory levels obtained from the CAPM. The results show that the CAPM yields present values for the cash flows which do not agree with the state prices of any of the investors. This is so because the CAPM implicitly assumes a unique pricing measure in the market. Therefore, a more general approach such as ours that recognizes the existence of multiple pricing kernels in the market and chooses a conservative valuation is necessary. In the rest of this section, we first illustrate the 
pure pooling solution, and then the pooling and tranching solution. The pure pooling solution does not depend on the short sales constraint on investors, whereas the pooling and tranching solution does.

Value of pure pooling. Clearly, not all values of $r_{1}, r_{2}$ and $r_{3}$ will lead to value creation. The optimal inventory quantity for each firm is zero if there is no value from pooling $X_{1}, X_{2}$, and $X_{3}$ in any proportion. This condition is given by Theorem 1(i). Upon applying this theorem, we find that there is no value from pooling if the reservation prices satisfy the following inequalities for some $a, b, c \in[0,1]$ :

$$
\frac{1}{3} a+b-r_{1} \leq 0, \quad \frac{1}{2} c-r_{2} \leq 0, \quad \frac{2}{3} a+\frac{1}{2} c-r_{3} \leq 0, \quad a+b+c=1
$$

The optimal inventory quantity for the three firms is 1 unit each if there is value from pooling and the pool is a grand coalition of the three products. This condition is given by Theorem 3 . We find that the grand coalition is sustainable if the reservation prices of the three assets satisfy the following inequalities for some $a, b, c \in[0,1]$ :

$$
\frac{1}{3} a+b-r_{1} \geq 0, \quad \frac{1}{2} c-r_{2} \geq 0, \quad \frac{2}{3} a+\frac{1}{2} c-r_{3} \geq 0, \quad a+b+c=1 .
$$

If neither system of inequalities, (11) or (12), has a feasible solution, then there is value from fractional pooling, i.e., the optimal inventory quantity is less than 1 for at least one firm.

To see these three solutions, we consider different values of reservation prices. Suppose that $r_{1}=0.2, r_{2}=0.3$ and $r_{3}=0.52$. Then, the system (11) is feasible, and thus, the optimal inventory quantity is 0 for each firm. If $r_{1}=0.17, r_{2}=0.33$ and $r_{3}=0.45$, then the system (12) is feasible, and the optimal inventory quantity is 1 for each firm. The total value is 0.05 , which can be divided among the firms in such a way as to sustain the grand coalition. If $r_{1}=0.25, r_{2}=0.4$ and $r_{3}=0.25$, then neither system of inequalities is feasible, implying that there is value from pooling but the grand coalition of the three products is not feasible. To find the maximal asset pool for these reservation prices, we solve the LP given in Corollary 2:

$$
\begin{aligned}
& \max \left\{z-0.25 \alpha_{1}-0.4 \alpha_{2}-0.25 \alpha_{3}:\right. \\
& \left.\quad 1 / 3 \alpha_{1}+2 / 3 \alpha_{3} \geq z, \alpha_{1} \geq z, 1 / 2 \alpha_{2}+1 / 2 \alpha_{3} \geq z, \alpha_{j} \in[0,1] \text { for all } j\right\} .
\end{aligned}
$$


Table 2: Optimal pooling and tranching solutions for different values of reservation prices when the intermediary has access to investors of type 2 only

\begin{tabular}{|c|c|c|c|c|c|c|c|}
\hline \multirow[b]{2}{*}{ Case } & \multirow[b]{2}{*}{$\begin{array}{l}\text { Reservation } \\
\text { prices }\end{array}$} & \multirow[b]{2}{*}{$\begin{array}{l}\text { Short sales } \\
\text { constraints }\end{array}$} & \multirow{2}{*}{$\begin{array}{l}\text { Optimal } \\
\text { inventory } \\
\left(\alpha_{1}, \alpha_{2}, \alpha_{3}\right)\end{array}$} & \multicolumn{3}{|l|}{ Tranches } & \multirow[b]{2}{*}{$\begin{array}{l}\text { Optimal } \\
\text { value }\end{array}$} \\
\hline & & & & $T^{a}$ & $\begin{array}{l}T^{m} \\
\left(\beta_{1}, \beta_{2}\right)\end{array}$ & $T^{I}$ & \\
\hline $\mathrm{A}$ & $0.2,0.3,0.52$ & Yes & $(1,1,1)$ & $(0,1,0,0)$ & $(0,2 / 3)$ & $(1 / 3,0,2 / 3,0)$ & 0.073 \\
\hline B & $0.2,0.3,0.52$ & No & $(1,0,1)$ & $(1,1,0,1)$ & $(0,0)$ & $(0,0,0,0)$ & 0.024 \\
\hline $\mathrm{C}$ & $0.17,0.33,0.45$ & Yes & $(1,1 / 3,1)$ & $(0,1,0,0)$ & $(0,2 / 3)$ & $(1 / 3,0,0,0)$ & 0.161 \\
\hline $\mathrm{D}$ & $0.17,0.33,0.45$ & No & $(1,0,1)$ & $(1,1,0,1)$ & $(0,0)$ & $(0,0,0,0)$ & 0.124 \\
\hline $\mathrm{E}$ & $0.25,0.4,0.25$ & Yes & $(1,1 / 3,1)$ & $(0,1,0,0)$ & $(0,2 / 3)$ & $(1 / 3,0,0,0)$ & 0.257 \\
\hline $\mathrm{F}$ & $0.25,0.4,0.25$ & No & $(0,0,1)$ & $(0,0,0,1)$ & $(0,0)$ & $(0,0,0,0)$ & 0.286 \\
\hline
\end{tabular}

Note: The optimal inventory for each firm determines its cash flow, and thus, the total cash flow of the asset pool. For the non-marketable tranches, $T^{a}$ and $T^{I}$, the table shows cash flows in each of the four states. For the marketable tranche, $T^{m}$, the table shows the weights, $\beta_{1}$ and $\beta_{2}$, of the two primary securities, $S_{1}$ and $S_{2}$. The optimal value shown in the last column is net of the cost of procurement of inventory at respective reservation prices of the firms.

Here, the decision variable $\alpha_{j}$ is the amount of inventory to be purchased by firm $j$ in the pool. The optimal solution is $\alpha_{1}=\frac{1}{2}, \alpha_{2}=0$, and $\alpha_{3}=1$, with an optimal value of $\frac{1}{8}$. The asset pool is given by $\left(\frac{1}{2}, \frac{1}{2}, 0,0\right)+(0,0,0,1)=\left(\frac{1}{2}, \frac{1}{2}, 0,1\right)$. The convex combination, $\frac{1}{4}$ of $Q_{2}$ and $\frac{3}{4}$ of $Q_{3}$, yields the pricing measure $q=\left(\frac{1}{4}, 0, \frac{3}{8}, \frac{3}{8}\right)$, under which $E_{q}\left[X_{1}\right]=\frac{1}{4}$ and $E_{q}\left[X_{3}\right]=\frac{3}{8}$, both of which are greater than or equal to the corresponding reservation prices. Thus, from Theorem 3 and Corollary 2 , this fractional pool is sustainable. Thus, the optimal decisions are for firm 1 to buy 0.5 units, firm 2 to buy 0 , and firm 3 to buy 1 unit, with a total value of $\frac{1}{8}$.

Value of pooling and tranching. In Table 6, we present the optimal tranching solutions corresponding to the reservation prices discussed above. We show the results both with and without constraints on short sales of primary securities by investors. In each case, we allow the intermediary to have access to investors of type 2 only. Thus, the intermediary can create tranches that are marketable or those that are priced for investors of type 2 , but not type 1 . In the table, we show the composition of the asset pool in the optimal solution, the structure of the tranches, and the total value obtained. The value of $m^{*}$ is obtained from the state prices in Table 1 for all cases.

In cases $\mathrm{A}$ and $\mathrm{B}$ in Table $2, r_{1}=0.2, r_{2}=0.3$, and $r_{3}=0.52$. When no short sales by investors are allowed, the optimal pooling and tranching solution gives the grand coalition of the three firms, i.e., $\alpha=(1,1,1)$. The value of the solution is 0.073 . Moreover, the dual solution to the pooling and tranching problem is $\lambda^{*}=(0.066,0.202,0.303,0.521)$. This gives $\sum_{k} \lambda_{k}^{*} X_{j}\left(\omega_{k}\right) \geq r_{j}$ for all $j$. 
Thus, the grand coalition is sustainable. Table 2 shows that the optimal solution consists of all three types of tranches, $T^{a}, T^{m}$, and $T^{I}$. When short sales by investors are allowed, the optimal solution is $\alpha=(1,0,1)$ and we pool $X_{1}$ and $X_{3}$, with a value of 0.024 . The dual solution to the pooling and tranching problem is $\lambda^{*}=(0.068,0.140,0.256,0.536)$. In this case, $\sum_{k} \lambda_{k}^{*} X_{2}\left(\omega_{k}\right)<r_{2}$, implying that firm 2's optimal inventory amount is 0 .

In cases $\mathrm{C}$ and $\mathrm{D}$, the values of reservation prices are $r_{1}=0.17, r_{2}=0.33$, and $r_{3}=0.45$. We find that $\sum_{k} \lambda_{k}^{*} X_{J}\left(\omega_{k}\right)<r_{j}$ for $j=2$ both with and without short sales constraints on investors. Thus, the grand coalition is not sustainable under pooling and tranching. With short sales constraints, the optimal solution is $\alpha=(1,1 / 3,1)$, with a value of 0.161 , and without short sales constraints, it is a different pool, $\alpha=(1,0,1)$, with a value of 0.124 . In cases $\mathrm{E}$ and $\mathrm{F}$, the values of reservation prices are $r_{1}=0.25, r_{2}=0.4$, and $r_{3}=0.25$. Again, the grand coalition is not sustainable under pooling and tranching both with and without short sales constraints, and we obtain results similar to cases $\mathrm{C}$ and $\mathrm{D}$.

In comparing pure pooling with pooling and tranching, we see that the latter yields a higher value for each instance of reservation prices shown above. The optimal pool under tranching may be larger or smaller than the optimal pool under pure pooling. In our example, it is larger in cases A, B and E, but smaller in cases C, D and F. Note that the structure of the tranches corresponds to Theorem 5(ii) in cases B, D and F, and Theorem 5(iii) in cases A, C and E. Similar results are obtained when the intermediary has access to investors of type 1 only or to both investor types.

In summary, due to the interaction with the financial market, securitization through pooling and tranching increases value and leads to a higher inventory procurement than if each firm had considered its inventory decision in isolation. The exact solution depends on the reservation prices since firms have to agree to join the coalition. While we considered simple inventory decisions, the same concept and methodology can be applied for more complex operational decisions. 


\section{Discussion}

Securitization has become a large and rapidly growing industry since the 1970s, with trillions of dollars of securitized assets. It has also come under criticism recently due to the events leading up to the financial crisis and economic recession of 2008-09. Our paper does not seek to analyze the practice of securitization, but studies the theoretical motivation for it. In this section, we reconcile the results of our paper with the practical challenges of securitization and suggest directions for future research.

One main result in our paper is that pooling and tranching are valuable in reducing ambiguity surrounding the valuation of new real investments in incomplete markets. These ideas are applicable to any operational decision, including, as we demonstrate, the newsvendor problem. Thus, the focus of this paper differs from securitization in practice, which deals with existing financial assets, and does not address new investment decisions. Further, our paper separately identifies the gains due to pooling and tranching. It shows that pure pooling is valuable even in the absence of tranching. In contrast, the implementation problems in securitization mostly deal with tranching and the associated issues of distance and information asymmetry. Our results imply that, in the simplest form, a large corporation could, instead of using a hurdle rate independently for each project, consider its set of projects and their costs (i.e., reservation prices) jointly and see if there are counter-balancing risks outside the marketed subspace that make the pool more valuable. These relationships can be used in future empirical research to compare the optimal pool with real investment decisions made by firms.

Another result of our paper relates to the construction of optimal tranches. In our optimal solution, tranches are formed by partitioning the cash flows on a state-by-state basis. The states in which a tranche has positive or zero cash flows are clearly defined. This contrasts with the practical implementation of mortgage-backed securities, in which tranches are formed using a subordination rule. Our tranches are categorized into three types that depend on spanning whereas the conventional ones only consider default regardless of whether the states are spanned. The information structure assumed by our model is simple and could be investigated in a practical setting. Addi- 
tionally, when there are different classes of investors with different marginal utilities, data for these investor classes could be used to design optimal tranches.

The practical implementation of securitization requires consideration of moral hazard, which is outside the scope of our model. In particular, Keys et al. (2008) analyze the subprime mortgage loans market, and find evidence that securitization led to lax screening of borrowers. They remark that the benefits of optimal securitization are limited by information loss in practice, but are not negated by it. Others have commented on the lack of "skin in the game" by lenders as well as other problems associated with rating agencies, regulation, and investors (Blinder (2007), Stiglitz (2007)). In the theoretical literature, the problem of moral hazard has been addressed in models of information asymmetry by requiring the issuer or financial intermediary to retain an equity tranche on its books. This approach can be used in conjunction with our model. More generally, in the literature, three sources of value from securitization have been identified - market frictions, information asymmetry, and market incompleteness. Our paper addresses the third mechanism, but all three mechanisms are important and are likely to occur in practice. Therefore, a practical implementation may benefit from recognizing all of them.

Our paper can be extended and modified in subsequent research in other ways. First, while the results in this paper are obtained under the strict definition of arbitrage, our analysis could be combined with price bounds derived under approximate arbitrage as in the recent literature. Under approximate arbitrage, market incompleteness should still continue to provide a rationale for seeking value enhancement through pooling and tranching. However, the imposition of a constraint that precludes "approximate arbitrage," instead of arbitrage, would restrict the set of feasible solutions to the optimization problems considered in this paper. Additional analysis is required to determine the optimal pooling and tranching strategies when subjected to the tighter constraints. Second, an interesting aspect of securitization is when the pool has to be created and managed dynamically. This problem is commonly faced by private equity and venture fund managers. The major differences are that firms within the pool might not have the option to leave the pool, while firms that enter later might enjoy greater bargaining power. Further, firms and the intermediary might have only an imperfect forecast about which assets will become available in the future. A 
third avenue for research is to compare the costs and benefits of alternative forms of financing in incomplete markets. While we studied the benefits of pooling and tranching in securitization, other types of financing may include issuance of new equity or debt. These alternatives may be analyzed in a partial equilibrium setting such as ours or a general equilibrium setting where investors are allowed to short sell the new assets so that the prices of existing assets in the market may change. Finally, future empirical research may seek to quantify the benefits of securitization for real investment decisions faced by firms in practice.

\section{References}

Allen, F., D. Gale. 1991. Arbitrage, Short Sales and Financial Innovation. Econometrica 59, 1041-1068.

Anvari, M. 1987. Optimality criteria and risk in inventory models: The case of the newsboy problem. Journal of the Operational Research Society 38(7) 625-632.

Artzner, P., F. Delbaen, J.-M. Eber, D. Heath. 1999. Coherent Measures of Risk. Mathematical Finance 9(3) 203-228.

Bernardo, A. E., O. Ledoit. 2000. Gain, Loss and Asset Pricing. Journal of Political Economy 108, 144-172.

Bertsimas, D., L. Kogan, A. Lo. 2001. Hedging Derivative Securities and Incomplete Markets: An $\epsilon$-Arbitrage Approach. Operations Research 49(3), 372-397.

Birge, J. 2000. Option Methods for Incorporating Risk into Linear Capacity Planning Models. MESOM 2(1), 19-31.

Birge, J., X. Xu. 2005. Operational Decisions, Capital Structure, and Managerial Compensation: A Newsvendor Perspective. Working Paper, Northwestern Univ.

Blinder, A. 2007. Six Fingers of Blame in the Mortgage Mess. New York Times September 30.

Buzacott, J., R. Zhang. 2004. Inventory Management with Asset-Based Financing. Management Science 50(9), 1274-1292. 
Cerny, A. 1999. Minimal Martingale Measure, CAPM, and Representative Agent Pricing in Incomplete Markets. Cass Business School Research Paper. Available at SSRN: http://ssrn.com/abstract=851188.

Cochrane, J. H. 2001. Asset Pricing. Princeton University Press.

Cochrane, J. H., J. Saa-Requejo. 2000. Beyond Arbitrage: Good-Deal Asset Pricing Bounds in Incomplete Markets. Journal of Political Economy 108, 79-119.

DeMarzo, P. M. 2005. The Pooling and Tranching of Securities: A Model of Informed Intermediation. Review of Financial Studies 18, 1-36.

DeMarzo, P. M., D. Duffie. 1999. A Liquidity Based Model of Security Design. Econometrica 67, 65-99.

Ding, Q., L. Dong, P. Kouvelis. 2007. On the Integration of Production and Financial Hedging Decisions in Global Markets. Operations Research 55, 470-489.

Dong, L., H. Liu. 2005. Equilibrium Forward Contracts on Nonstorable Commodities in the Presence of Market Power. Operations Research 55, 128-145.

Ekern, S., R. Wilson. 1974. On the Theory of the Firm in an Economy with Incomplete Markets. The Bell Journal of Economics and Management Science 5(1), 171-180.

Fink, R. 2002. Beyond Enron. CFO Magazine February 1, 2002.

Gaur, V., S. Seshadri. 2005. Hedging Inventory Risk through Market Instruments. MESOM 7(2), 103-120.

Geanakoplos, J., M. Shubik. 1990. The capital asset pricing model as a general equilibrium with incomplete markets. Journal The GENEVA Papers on Risk and Insurance 15(1), 55-71.

Glaeser, E., H. Kallal. 1997. Thin Markets, Asymmetric Information, and Mortgage-Backed Securities. Journal of Financial Intermediation 6, 64-86.

Gorton, G. B., G. Pennacchi. 1990. Financial Intermediaries and Liquidity Creation. Journal of Finance 45, 49-71. 
Gorton, G. B., N. S. Souleles. 2005. Special Purpose Vehicles and Securitization. FRB Philadelphia Working Paper No. 05-21. Available at SSRN: http://ssrn.com/abstract=713782.

Gourdon, C. S., C. Reynolds. 2001. Asset Monetization. Monitor 28(2) February 2001.

Hansen, L. P., R. Jagannathan. 1991. Implications of Security Market Data for Models of Dynamic Economies. Journal of Political Economy 99, 225-262.

Harrison, M., D. Kreps. 1979. Martingales and Arbitrage in Multiperiod Securities Markets. Journal of Economic Theory 20, 281-408.

Huchzermeier, A., M. Cohen. 1996. Valuing Operational Flexibility Under Exchange Rate Risk. Operations Research 44(1), 100-113.

Keys, B. J., T. K. Mukherjee, A. Seru, V. Vig. 2008. Did Securitization Lead to Lax Screening? Evidence from Subprime Loans. EFA 2008 Athens Meetings Paper. Available at SSRN: http://ssrn.com/abstract $=1093137$.

Kogut, B., N. Kulatilaka. 1994. Operating Flexibility, Global Manufacturing, and the Option Value of Multinational Network. Management Sci. 40(1), 123-139.

Kouvelis, P. 1999. Global Sourcing Strategies Under Exchange Rate Uncertainty, Chapter 20 in Quantitative Models For Supply Chain Management. Eds. S. Tayur, R. Ganeshan, M. Magazine. Kluwer Academic Publishers, Boston.

Leland, H., D. Pyle. 1977. Information Asymmetries, Financial Structure and Financial Intermediaries. Journal of Finance 32, 371-387.

Levy, H. 1985. Upper and Lower Bounds of Put and Call Option Value: Stochastic Dominance Approach. Journal of Finance 40, 1197-1217.

Li, L., M. Shubik, M. Sobel. 2005. Control of Dividends, Capital Subscriptions, and Physical Inventories. Working Paper, Yale School of Management.

Magill, M., M. Quinzii. 2002. Theory of Incomplete Markets. MIT Press. 
Mas-Colell, A., M. D. Whinston, J. R. Green. 1995. Microeconomic Theory. Oxford University Press.

Mathur, K., P. Ritchken. 1999. Minimum Option Prices under Decreasing Absolute Risk Aversion. Review of Derivative Research 3, 135-156.

Mayers, D. 1973. Nonmarketable Assets and the Determination of Capital Asset Prices in the Absense of a Riskless Asset. Journal of Business 46(2), 258-267.

Mayers, D. 1976. Nonmarketable Assets, Market Segmentation, and the Level of Asset Prices. Journal of Financial and Quantitative Analysis 11(1), 1-12.

Murty, K. G. 1983. Linear Programming. John Wiley \& Sons.

Owen, G. 1975. On the Core of Linear Production Games. Mathematical Programming 358-370.

Owen, G. 1995. Game Theory. 3rd ed. Academic Press.

Perrakis, S., P. Ryan. 1984. Option Pricing in Discrete Time. Journal of Finance 39, 519-525.

Pliska, S. R. 1997. Introduction to Mathematical Finance: Discrete Time Models. Blackwell Publishers, Malden, MA.

Ritchken, P. 1985. On Option Pricing Bounds. Journal of Finance 40, 1219-1233.

Ritchken, P., S. Kuo. 1988. Option Pricing with Finite Revision Opportunities. Journal of Finance 43, 301-308.

Shanken, J. 1992. The Current State of the Arbitrage Pricing Theory. Journal of Finance 47, 1569-1574.

Smith, J., K. McCardle. 1999. Options in the Real World: Lessons Learned in Evaluating Oil and Gas Investments. Operations Research 47(1) 1-15.

Stiglitz, J. 2007. Houses of Cards. The Guardian October 9. 
Subrahmanyam, A. 1991. A Theory of Trading in Stock Index Futures. Review of Financial Studies 4, 17-51.

Tavakoli, J. M. 2003. Collateralized Debt Obligations and Structured Finance: New Developments in Cash and Synthetic Securitization. Wiley Finance.

Van Mieghem, J. 2003. Capacity Management, Investment and Hedging: Review and Recent Developments. MESOM 5(4), 269-302.

Weil, P. 1994. Nontraded assets and the CAPM. European Economic Review 38(3-4), 913-922.

\section{Appendix}

\section{A. Application of the CAPM to the numerical example in $\S 6$}

The application of the CAPM to our numerical example serves two purposes. It illustrates the equivalence of our approach with the CAPM for the valuation of traded securities in the market. It also shows that the CAPM does not lead to unambiguous definition of value for assets that are outside the span of the market. Therefore, a more general approach such as ours is necessary.

To apply the CAPM, we need to translate it into a mean-variance setting. Therefore, we regress the payoffs of the three new assets, $X_{1}, X_{2}$ and $X_{3}$ on the payoffs of the two primary securities, $S_{1}$ and $S_{2}$. The regression is done using minimum weighted least squares using the subjective probabilities of the four states as weights. The intuitive explanation is that if we observed these returns repeatedly, then the number of observations of each cash flow will be proportional to the subjective probabilities. Thus, a regression on these historical returns would yield the same equation.

Further, note that instead of a single-factor asset pricing model, we use a two-factor model with $S_{1}$ and $S_{2}$ representing the two factors. $S_{1}$ is a risk free bond in our example, but in general, it need not be. This approach is described in Cochrane (2001: p.80-82). Usually, the factors in a multi-factor model are proxies for aggregate consumption. Here, $S_{1}$ and $S_{2}$ represent only the traded portion of aggregate consumption in our model. Thus, the application of the CAPM ignores the non-traded portion of investors' endowment; see Mayers $(1973,1976)$ for an extension of the 
CAPM to incorporate non-traded assets.

The regression results are functions of the inventory levels $\alpha_{1}, \alpha_{2}$ and $\alpha_{3}$. They are given by:

$$
\begin{aligned}
& X_{1}\left(\alpha_{1}\right)=0.94 \alpha_{1} S_{1}-0.44 \alpha_{1} S_{2}+\text { error } \\
& X_{2}\left(\alpha_{2}\right)=0.48 \alpha_{2} S_{1}-0.33 \alpha_{2} S_{2}+\text { error } \\
& X_{3}\left(\alpha_{3}\right)=-0.43 \alpha_{3} S_{1}+0.78 \alpha_{3} S_{2}+\text { error }
\end{aligned}
$$

Here, $\alpha_{1}, \alpha_{2}, \alpha_{3} \in[0,1]$. By definition, the residuals sum to zero. Therefore, the regression equations give us the prices of $X_{1}, X_{2}$ and $X_{3}$ at time 0 as functions of inventory levels, which can then be used to compute the optimal inventory for each firm. For $X_{1}$, we get the price of $0.5 \alpha_{1}$. Thus, the optimal inventory level for firm 1 is 1 unit if the procurement price $r_{1}$ is less than 0.5 , and 0 otherwise. Likewise, the prices of $X_{2}$ and $X_{3}$ are $0.15 \alpha_{2}$ and $0.35 \alpha_{3}$, respectively. Thus, firm 2 would buy 1 unit of inventory if $r_{2}<0.15$, and firm 3 would buy 1 unit of inventory if $r_{3}<0.35$.

There are two problems with the above approach. First, the CAPM implies a unique pricing measure. The above prices computed from the CAPM correspond to the pricing measure, $(0.40$, $0.10,0.15,0.35)$. This measure belongs to our set $\Theta$, which is not surprising since the CAPM is equivalent to our discount factor model for traded assets. ${ }^{11}$ However, its uniqueness is a strong assumption since the market in our example is incomplete. In contrast to this assumption, our analysis shows that there is an infinite number of pricing kernels admissible in the market, which is why we conservatively uses the minimum value to price the untraded assets over the set of these kernels.

Further, the pricing measure implied by the CAPM is not equal to the state prices of either of the two investor types as shown in Table 1 . This shows that investors may not agree with the CAPM prices and will debate on prices since $X_{1}, X_{2}$ and $X_{3}$ are outside the span of the market. Therefore, the CAPM does not lead to an unambiguous definition of value for non-traded assets, even though it gives a pricing measure consistent with our model and thus provides the same

\footnotetext{
${ }^{11}$ The existence of the pricing measure is noteworthy because the problem to find the pricing measure has three unknowns (for four states) and five constraints (for the five securities), which may be an infeasible problem in general. We also note that it is a coincidence that this pricing measure is equal to the subjective probability measure; this is not true in general.
} 
valuation of traded assets.

\section{B. Proofs}

Proof of Lemma 1. We prove part (i). The proof for part (ii) is similar. Consider the linear program:

$$
\min \left\{z: z \geq \sum_{k=1}^{K} q_{l}\left(\omega_{k}\right) Z\left(\omega_{k}\right) \forall l=1, \ldots, L, z \text { unsigned. }\right\}
$$

If $z \geq \sum_{k} q_{l}\left(\omega_{k}\right) Z\left(\omega_{k}\right)$ for all $l$, then $\sum_{l} \delta_{l} z \geq \sum_{l} \sum_{k} \delta_{l} q_{l}\left(\omega_{k}\right) Z\left(\omega_{k}\right)$ for all $\delta_{l} \geq 0, \sum_{l} \delta_{l}=1$. Thus, $z \geq \sup _{q \in \Theta} E_{q}\left[Z\left(\omega_{k}\right)\right]$. Therefore, the optimal solution to the linear program must be greater than or equal to $V^{+}(Z)$. On the other hand, $z=\max _{l \in L} E_{q_{l}}[Z]$ is a feasible solution to the linear program. But $\max _{l \in L} E_{q_{l}}[Z] \leq \sup _{q \in \Theta} E_{q}\left[Z\left(\omega_{k}\right)\right]$. Thus, $V^{+}(Z)=\max _{l \in L} E_{q_{l}}[Z]$.

For the proof of part (iii), consider the problem of maximizing the minimum marketable value of a claim $Z$ that pays $Z\left(\omega_{k}\right)$ is state $k$.

$$
\max \left\{\sum_{n} \alpha_{n} p_{n}: \sum_{n} \alpha_{n} S_{n}\left(\omega_{k}\right) \leq Z\left(\omega_{k}\right) \forall k=1, \ldots, K, \alpha_{n} \text { unsigned } \forall n=1, \ldots, N .\right\}
$$

The objective is to maximize the market value of a portfolio of primary securities that pays less cash flows than claim $Z$ in every state $k$. The dual of this problem is given by:

$$
\min \left\{\sum_{k} \lambda_{k} Z\left(\omega_{k}\right): \sum_{k} \lambda_{k} S_{n}\left(\omega_{k}\right)=p_{n} \forall n=1, \ldots, N, \lambda_{k} \geq 0 \forall k=1, \ldots, K .\right\}
$$

We require that $\sum_{k} \lambda_{k}^{*} S_{n}\left(\omega_{k}\right)=p_{n}$ for every security $n$ in the optimal dual solution. But this condition, by definition, implies that the optimal dual solution is a pricing measure that belongs to the set $\Theta$. The proof follows by applying part (i) of the lemma. The validity of the upper bound can be proven similarly.

Proof of Theorem 1. To prove (i) of the theorem, we show the equivalent statement that if value can be created by pooling, then there does not exist any $q \in \Theta$ such that $E_{q}\left[X_{j}\right] \leq r_{j}$ for all $j$. Consider the linear program:

$$
\max \left\{v-\sum_{j} \alpha_{j} r_{j}:-\sum_{k} q_{l}\left(\omega_{k}\right) \sum_{j} \alpha_{j} X_{j}\left(\omega_{k}\right)+v \leq 0 \forall l=1, \ldots, L, \alpha_{j} \geq 0 \forall j=1, \ldots, J .\right\}
$$


Here, the vector $\left(\alpha_{j}\right)$ denotes the proportion in which the assets $\left(X_{j}\right)$ are pooled together, and $v$ denotes the value of the asset pool in the securities market. The value of the asset pool is defined as $V^{-}\left(\sum_{j} \alpha_{j} X_{j}\right)$ because this is the minimum price that the asset pool commands in the securities market. To compute the value of the asset pool, we have used Lemma 1, i.e., the expected value under each extreme pricing measure, $q_{l}$, should be greater than or equal to the value $v$. The first $L$ constraints correspond to these requirements. The linear program seeks to obtain the combination of assets that will maximize the difference between its value $v$ and the combination of reservation prices required to create the asset pool, $\sum_{j} \alpha_{j} r_{j}$.

If value can be created by pooling, then there exist weights $\alpha_{j}$ such that the linear program is feasible and

$$
v-\sum_{j} \alpha_{j} r_{j}>0
$$

Let $\theta_{l} \geq 0$ be any set of weights such that $\sum_{l} \theta_{l}=1$. Multiply each of the $L$ constraints with the corresponding weight $\theta_{l}$ and add. Because the linear program is feasible, we get

$$
-\sum_{k} \sum_{l} \theta_{l} q_{l}\left(\omega_{k}\right)\left(\sum_{j} \alpha_{j} X_{j}\left(\omega_{k}\right)\right)+v \leq 0
$$

Here, $\sum_{l} \theta_{l} q_{l}$ is a pricing measure in $\Theta$, which we denote by $q$. Hence, (14) can be rewritten as

$$
-E_{q}\left[\sum_{j} \alpha_{j} X_{j}\right]+v \leq 0
$$

Combining (13) and (15), we get $E_{q}\left[\sum_{j} \alpha_{j} X_{j}\right]>\sum_{j} \alpha_{j} r_{j}$. Equivalently, there exists $j$ such that $E_{q}\left[X_{j}\right]>r_{j}$

Since $\theta_{l}$ are arbitrary and the pricing measures constructed using the set $\left\{\left(\theta_{l}\right): \theta_{l} \geq 0, \sum_{l} \theta_{l}=\right.$ 1) are a superset of $\Theta$, we conclude that, if value can be created by pooling, then there does not exist any $q \in \Theta$ such that $E_{q}\left[X_{j}\right] \leq r_{j}$ for all $j$.

To prove (ii), consider the dual of the above linear program. The dual variables $\mu_{l}$ will be associated with each of the constraints related to the expected value under extreme pricing measure $q_{l}$. The dual problem is:

$$
\min \left\{0: \sum_{l} \mu_{l}=1, \sum_{k} \sum_{l} \mu_{l} q_{l}\left(\omega_{k}\right) X_{j}\left(\omega_{k}\right) \leq r_{j} \forall j=1, \ldots, J, \mu_{l} \geq 0 \forall l=1, \ldots, L .\right\}
$$


We wish to show that if no value can be created by pooling, then there exists $q \in \Theta$ such that $E_{q}\left[X_{j}\right] \leq r_{j}$ for all $j$. Notice that by choosing all $\alpha_{j}=0$, the primal problem is always feasible and has a lower bound of zero. The only question is whether the primal has a bounded solution which by strong duality theorem can only be zero from the dual program's objective function - or an unbounded solution. The former situation is the one where pooling does not create value (and the dual is feasible), and the latter situation is the one where pooling leads to value creation (and the dual is infeasible). Thus, if no value can be created by pooling, then the primal has a bounded solution and the dual is feasible. From the dual constraints, we observe that dual feasibility implies that there exist weights $\mu_{l}$ such that under the pricing measure $\sum_{l} \mu_{l} q_{l}$, we have $E\left[X_{j}\right] \leq r_{j}$ for all $j$. This proves the converse.

Proof of Theorem 2. We first show the proof of this theorem for partitions where $w_{j}=0$ or 1 and then extend it to the case of fractional $w_{j}$. Since we restrict $w_{j}$ to be 0 or 1 , we denote the cash flows for any subset $J_{w}$ of $J$ simply as $\sum_{j \in J_{w}} X_{j}$ and the corresponding reservation prices as $\sum_{j \in J_{w}} r_{j}$

The proof of part (i) of the theorem follows from the work of Owen (1975). We sketch the proof for completeness. Consider the problem of maximizing the value of the portfolio formed from the assets of coalition $J_{w}$ by selling tranches of primary securities against it. The maximum value is given by solving the linear program:

$$
\max \left\{\sum_{n} \beta_{n} p_{n}: \sum_{n} \beta_{n} S_{n}\left(\omega_{k}\right) \leq \sum_{j \in J_{w}} X_{j}\left(\omega_{k}\right) \forall k=1, \ldots, K, \beta_{n} \geq 0 \forall i=1, \ldots, N .\right\}
$$

The dual to this problem is

$$
\min \left\{\sum_{k} \lambda_{k} \sum_{j \in J_{w}} X_{j}\left(\omega_{k}\right): \sum_{k} \lambda_{k} S_{n}\left(\omega_{k}\right) \geq p_{n} \forall n=1, \ldots, N, \lambda_{k} \geq 0 \forall k=1, \ldots, K .\right\}
$$

Notice that the constraints to the dual program do not depend on the coalition formed because the $X_{j}$ 's enter only the objective function. Moreover, the dual is feasible because the market is arbitrage-free, that is, any $q \in \Theta$ will satisfy the dual constraints, i.e., $\sum_{k} q_{k} S_{n}\left(\omega_{k}\right)=p_{n}, \forall n, q \in \Theta$. Finally, as $X_{j}\left(\omega_{k}\right) \geq 0$ for all $j$, the solution to the dual program is finite, as it cannot drop below 
zero. Solve the problem for the grand coalition of all firms and obtain the optimal dual solution $\lambda_{k}^{*}$. As $X_{j}\left(\omega_{k}\right) \geq 0$ for all $j$, by applying the same reasoning as in Lemma 1(iii), we can also assume that these dual values constitute a pricing measure in $\Theta$.

Consider the following solution to the cooperative game: Let firm $j$ receive the payment $\sum_{k} \lambda_{k}^{*} X_{j}\left(\omega_{k}\right)$. This is surely greater than or equal to $V^{-}\left(X_{j}\right)$, and therefore, by assumption, larger than $r_{j}$. By definition, the coalition $J_{w}$ receives the sum of the payments to the firms in the coalition. This sum equals or exceeds the maximum value obtained by solving the linear program for just the coalition because: (a) the $\lambda_{k}^{*}$ 's constitute a dual feasible solution to the problem for all $J_{w} \subseteq J$ because, as noted earlier, the constraints of the dual problem do not depend on the coalition formed; and (b) all dual feasible solutions are greater than or equal to the primal optimal solution (by weak duality). This proves part (i).

For the proof of part (ii), the problem is to demonstrate the existence of a payment scheme that works for all coalitions simultaneously. Redefine the value of a coalition without loss of generality to be $V\left(J_{w}\right)=\max \left(V^{-}\left(J_{w}\right), \sum_{j \in J_{w}} r_{j}\right)$. We first show that if the condition stated in part (ii) applies to partitions comprised of two subsets, then it also applies to any arbitrary partition. That is, if for every subset $J_{w}$ of $J$, we have $V(J) \geq \max \left(V\left(J_{w}\right), \sum_{j \in J_{\alpha}} r_{j}\right)+\max \left(V\left(J_{w}^{c}\right), \sum_{j \in J_{w}^{c}} r_{j}\right)$, then for every partition $J_{1}, J_{2}, \ldots, J_{k}$ of $J$, the same inequalities hold. (Note that the reverse statement can also be proven, implying that the two conditions are equivalent.) The proof is by contradiction. Assume that the condition does not hold for some partition, $J_{1}, J_{2}, \ldots, J_{k}$. Thus, by assumption,

$$
V(J)<\sum_{i} \max \left(V^{-}\left(J_{i}\right), \sum_{j \in J_{i}} r_{j}\right) .
$$

Without loss of generality, assume that for $i=1,2, \ldots, h, \max \left(V^{-}\left(J_{i}\right), \sum_{j \in J_{i}} r_{j}\right)=V^{-}\left(J_{i}\right)$, and for $i=h+1, h+2, \ldots, k, \max \left(V^{-}\left(J_{i}\right), \sum_{j \in J_{i}} r_{j}\right)=\sum_{j \in J_{i}} r_{j}$. Then, by super-additivity of the value function (which follows from the definition of $V^{-}$),

$$
V^{-}\left(\bigcup_{i=1}^{h} J_{i}\right) \geq \sum_{i=1}^{h} V^{-}\left(J_{i}\right) .
$$

Let $J_{w}=\bigcup_{i=1}^{h} J_{i}$. By the condition given in part (ii) of Theorem 2, the definition of $V(\cdot)$, and the 
discussion above, we have

$$
\begin{aligned}
V(J) & \geq V\left(J_{w}\right)+V\left(J_{w}^{c}\right) \\
& \geq \sum_{i=1}^{i=h} V^{-}\left(J_{i}\right)+\sum_{j=h+1}^{k} \sum_{j \in J_{i}} r_{j} \\
& =\sum_{i} \max \left(V^{-}\left(J_{i}\right), \sum_{j \in J_{i}} r_{j}\right) .
\end{aligned}
$$

This provides the necessary contradiction. The proof of part (ii) now appears to be immediate because, under every solution in the core, each coalition $J_{w}$ gets at least $\max \left(V\left(J_{w}\right), \sum_{j \in J_{w}} r_{j}\right)$. Thus, the payment is sufficient to cover the reservation price. However, it must further be shown that this can be done simultaneously for every coalition and not just coalition by coalition.

Consider the primal problem:

$$
\min 0
$$

subject to

$$
\begin{aligned}
\sum_{j \in J_{w}} \pi_{j} & \geq V\left(J_{w}\right), \quad \text { for all } J_{w} \subseteq J, \\
\sum_{j} \pi_{j} & =V(J), \\
\pi_{j} & \geq 0, \quad \text { for all } j .
\end{aligned}
$$

This program if feasible determines the payment schedule for the firms, i.e., firm $j$ receives a payment $\pi_{j}$. The dual problem is:

$$
\max \sum_{J_{w} \subseteq J} \lambda_{J_{w}} V\left(J_{w}\right)+\lambda V(J)
$$

subject to

$$
\begin{aligned}
\sum_{J_{w}: j \in J_{w}} \lambda_{J_{w}}+\lambda & \leq 0, \quad j=1, \ldots, J \\
\lambda_{J_{w}} & \geq 0, \quad \lambda \text { unsigned. }
\end{aligned}
$$

The dual variables $\lambda_{J_{w}}$ correspond to the first set of constraints in the primal problem, and the dual variable $\lambda$ corresponds to the second constraint. Obviously, the dual problem is always feasible (set all variables equal to zero). The dual solution will equal zero. Moreover, $\lambda$ has to be less than 
or equal to zero. All we need to show is that zero is the maximum possible solution to the dual. If not, then the dual will be unbounded (by scaling all variables as large as desired), and therefore, the primal will be infeasible. We proceed to show that the solution to the dual problem is bounded.

Consider the constraint to the dual corresponding to $j=1$. This constraint along with $\lambda \leq 0$ implies that:

$$
\sum_{J_{w}: 1 \in J_{w}} \lambda_{J_{w}} V\left(J_{w}\right)+\lambda \max \left(V\left(J_{w}\right): 1 \in J_{w}, J_{w} \subseteq J\right) \leq 0 .
$$

Similarly, the constraint corresponding to $j=2$ yields

$$
\sum_{J_{w}: 2 \in J_{w} \text { and } 1 \in J_{w}^{c}} \lambda_{J_{w}} V\left(J_{w}\right)+\lambda \max \left(V\left(J_{w}\right): 2 \in J_{w} \text { and } 1 \in J_{w}^{c}, J_{w} \subseteq J\right) \leq 0 .
$$

We can write analogous inequalities for larger values of $j$. In general, we have

$\sum_{J_{w}: j \in J_{w} \text { and }\{1, \ldots, j-1\} \subseteq J_{w}^{c}} \lambda_{J_{w}} V\left(J_{w}\right)+\lambda \max \left(V\left(J_{w}\right): j \in J_{w}\right.$ and $\left.\{1, \ldots, j-1\} \subseteq J_{w}^{c}, J_{w} \subseteq J\right) \leq 0$.

The sets where the maximum is attained over $\left(J_{w}: j \in J_{w}\right.$ and $\left.\{1, \ldots, j-1\} \subseteq J_{w}^{c}, J_{w} \subseteq J\right)$ are disjoint and their union is less than or equal to $J$. Adding up these inequalities gives

$$
\sum_{J_{w} \subseteq J} \lambda_{J_{w}} V\left(J_{w}\right)+\lambda\left(\max \left(V\left(J_{w}\right): 1 \in J_{w}, J_{w} \subseteq J\right)+\max \left(V\left(J_{w}\right): 2 \in J_{w} \text { and } 1 \in J_{w}^{c}, J_{w} \subseteq J\right)+\ldots\right) \leq 0
$$

Recalling that $V(J)$ is greater than equal to the sum of the $V\left(J_{i}\right)$ 's over any partition of $J$ we obtain

$$
\sum_{J_{w} \subseteq J} \lambda_{J_{w}} V\left(J_{w}\right)+\lambda V(J) \leq 0 .
$$

Therefore, the optimal value of the dual problem is bounded above by zero. This implies that the dual problem is feasible and bounded, and therefore, has an optimal solution. Therefore, by strong duality theorem, the primal has a feasible solution.

This proves the theorem for $w_{j}=0$ or 1 for all $j$. The same proof applies for the case of fractional $w_{j}$ when the number of subdivisions of each asset is finite. Thus, if each asset is broken into a finite number of parts, treating each subdivided asset as a 'undivided' asset we get the result. 
Proof of Theorem 3. Consider a partition of the assets, such that one coalition pools $\sum_{j} w_{j} X_{j}$ with a reservation price of $\sum_{j} w_{j} r_{j}$ and the other coalition pools $\sum_{j}\left(1-w_{j}\right) X_{j}$ with a reservation price of $\sum_{j}\left(1-w_{j}\right) r_{j}$. By assumption, $\sum_{j} E_{q_{l}} w_{j} X_{j} \geq \sum_{j} w_{j} r_{j}$, and by definition $\sum_{j} E_{q_{l}} w_{j} X_{j} \geq$ $V^{-}\left(\sum_{j} w_{j} X_{j}\right)$. Thus, $\sum_{j} E_{q_{l}} w_{j} X_{j} \geq \max \left(\sum_{j} w_{j} r_{j}, V^{-}\left(\sum_{j} w_{j} X_{j}\right)\right)$. Similarly, $\sum_{j} E_{q_{l}}\left(1-w_{j}\right) X_{j} \geq$ $\max \left(\sum_{j}\left(1-w_{j}\right) r_{j}, V^{-}\left(\sum_{j}\left(1-w_{j}\right) X_{j}\right)\right)$. Adding these, we get

$$
V^{-}\left(\sum_{j} X_{j}\right) \geq \max \left(V^{-}\left(\sum_{j} w_{j} X_{j}\right), \sum_{j} w_{j} r_{j}\right)+\max \left(V^{-}\left(\sum_{j}\left(1-w_{j}\right) X_{j}\right), \sum_{j}\left(1-w_{j}\right) r_{j}\right) .
$$

This proves the sufficiency part of the theorem.

For the necessity part, suppose that the solution with $w_{j}=1$ for all $j$ is in the core, but the condition in Theorem 3 does not hold, i.e., for each $q \in \Theta$ that achieves $V^{-}\left(\sum_{j} X_{j}\right)$, there exists a firm $j$ such that $E_{q}\left[X_{j}\right]<r_{j}$. Consider the following linear program:

$$
\max v-\sum_{j} w_{j} r_{j}
$$

subject to

$$
\begin{aligned}
& v-\sum_{j} w_{j} E_{q_{l}}\left(X_{j}\right) \leq 0 \quad \text { for all } l, \\
& w_{j} \leq 1 \quad \text { for all } j, \\
& v \text { unsigned, } \quad w_{j} \geq 0 \quad \text { for all } j \text {. }
\end{aligned}
$$

This LP seeks the optimal fractions $\left(w_{j} \in[0,1]\right)$ of all assets $X_{j}$ to construct the asset pool if we can buy the claim $w_{j} X_{j}$ for the reservation price $w_{j} r_{j}$ and the objective is to maximize the value of the pool. The $q_{l}$ are the extreme risk-neutral pricing measures. The dual program is

$$
\min \sum_{j} \gamma_{j}
$$

subject to

$$
\begin{gathered}
\sum_{l} \lambda_{l}=1, \\
-\sum_{l} \lambda_{l} E_{q_{l}}\left(X_{j}\right)+\gamma_{j} \geq-r_{j} \quad \text { for all } j, \\
\gamma_{j}, \lambda_{l} \geq 0 \quad \text { for all } j, l .
\end{gathered}
$$


In this formulation, the $\lambda_{l}$ 's are the dual variables corresponding to the first set of primal constraints, and the $\gamma_{j}$ 's are the dual variables corresponding to the second set of primal constraints. Suppose that the optimal solution to the dual problem is achieved at some values $\lambda_{l}^{*}, \gamma_{j}^{*}$. Let $q^{*} \in \Theta$ be such that $\sum_{l} \lambda_{l}^{*} q_{l}=q^{*}$. By assumption, the optimal solution to the primal problem is $w_{j}^{*}=1$ for all $j$, and $v^{*}=V^{-}\left(\sum_{j} X_{j}\right)-\sum_{j} r_{j}$. By complementary slackness applied to $w_{j}^{*}$ variables, we get that the second constraint in the dual problem must be binding for all $j$ in the optimal solution. Thus, we have $\gamma_{j}^{*}=E_{q^{*}}\left[X_{j}\right]-r_{j}$ for all $j$, and since $\gamma_{j}^{*} \geq 0$, we further have $E_{q^{*}}\left[X_{j}\right] \geq r_{j}$ for all $j$. Thus, the optimal solution to the dual problem is $E_{q^{*}}\left[\sum_{j} X_{j}\right]-\sum_{j} r_{j}$. Equating this to the optimal primal solution, we get that $q^{*}$ achieves the lower bound on the price of the pool, i.e., $E_{q^{*}}\left[\sum_{j} X_{j}\right]=V^{-}\left(\sum_{j} X_{j}\right)$. By assumption, this implies that there must be some firm $j^{*}$ for which the second constraint in the dual problem has a slack, i.e., $E_{q^{*}}\left(X_{j^{*}}\right)<r_{j^{*}}$. However, this gives a contradiction, and thus, proves the necessity part of the theorem.

Proof of Corollary 1. The choice of $q_{p}$ in part (i) follows from Lemma 1. Notice that when the lower bound, $V^{-}\left(\sum_{j} X_{j}\right)$, is achieved at several extreme points then a linear mixture of these measures also gives the same lower bound. The second part follows from part (ii) of Theorem 2 . To see this, the optimal solution to the grand coalition's problem is the highest value that can be obtained by pooling all assets, which must equal $E_{q_{p}}\left(\sum_{j} X_{j}\right)$. Moreover, any linear pricing measure that supports the core must be an optimal dual solution to the problem of determining $V^{-}\left(\sum_{j} X_{j}\right)$. Also, all optimal solutions to the dual problem are obtained as convex combinations of the optimal extreme points solutions. Thus, if one such pricing measure can be found that not only supports the core but also gives a value of each $X_{j}$ larger than $r_{j}$, then all firms will willingly participate in creation of the pool.

Proof of Corollary 2. The value is maximized because this is the highest surplus that can be generated after meeting all the reservation prices. The set of projects financed is maximal because if another project could be added to the set with an increase to the objective function then the current solution is not optimal.

Let $q$ be the measure under which the pooled assets attain their minimal value. Then, if asset 
$j$ is at a positive level in the pool then, $E_{q} X_{j}>r_{j}$ otherwise the dual constraint of the form $-E_{q} X_{j}+\gamma>-r_{j}$ will have slack, which will mean that the asset $j$ is at zero level in the primal solution. Also, the set of assets $w_{j} X_{j}$ satisfy the conditions of Theorem 3 .

To show that the remaining assets cannot be pooled to create value, observe that under the extreme pricing measure that minimizes the value of the pooled fractions of assets, the expected value of the unpooled fractions of each asset is below its reservation price. Thus, applying Theorem 1(i) we get the result.

Proof of Lemma 2. We first note that the dual problem $D^{T}(J)$ has a feasible solution located in the bounded convex set given by the intersection of the set of feasible region of problem $D^{T}(J)$ and $\mathcal{B}=\prod_{k}\left[0, \max \left(1, \max _{k} m_{k}^{*}\right)\right] \times\left[0, \max \left(1, \max _{k} m_{k}^{*}\right)\right]$. The proof of this assertion follows from the fact that $q_{k} \leq 1$, so that we may bound the region in which we search for a feasible solution by a hypercube that contains the largest values of $\lambda_{k}$ and $\delta_{k}$.

The proof of Lemma 2 now follows from the facts that the optimal dual solution is bounded above by a feasible solution in $\mathcal{B}$, and that the minimum is attained at an extreme point of $\mathcal{B} \cap S_{D^{T}}$ (cf: Lemma 1).

Proof of Theorem 4. (i) Assume to the contrary that there exists a solution to the dual problem, $D^{T}(J)$, in $\Theta$. This solution must be obtained by setting $\delta=0$ and $\lambda=q$ for some $q \in \Theta$. Since the solution must satisfy all the dual constraints, multiplying constraints (7) by $Z\left(\omega_{k}\right)$ and adding, we get $\sum_{k} \lambda_{k} Z\left(\omega_{k}\right) \geq \sum_{k} m_{k}^{*} Z\left(\omega_{k}\right)$. However, this gives a contradiction because $\sum_{k} \lambda_{k} Z\left(\omega_{k}\right)=$ $\sum_{k} q_{k} Z\left(\omega_{k}\right)<V^{+}(Z)$. Therefore, there is no feasible solution to the dual problem in $\Theta$. Further, since $\lambda \notin \Theta$, we must have $\delta_{k}>0$ in some state $k$, so that $\Omega^{a} \neq \emptyset$.

(ii) Assume to the contrary that there exists a non-negative contingent claim $Z$ such that $\sum_{k} m_{k}^{*} Z\left(\omega_{k}\right)>V^{+}(Z)$ but which is zero in all states in $\Omega^{a}$. Let $\left(\lambda_{k}^{*}, \delta_{k}^{*}\right)$ denote the optimal solution of the dual problem. Because $Z\left(\omega_{k}\right)=0$ for all $k \in \Omega^{a}$, we can set $m_{k}^{*}=0$ for these states. Since $\delta_{k}^{*}=0$ for all $k$ solves the dual problem with $Z$ as the asset pool, we have a feasible $\lambda \in \Theta$. Thus, applying the same step as in the proof of (i) above, we find that $\sum_{k} \lambda_{k} Z\left(\omega_{k}\right) \geq \sum_{k} m_{k}^{*} Z\left(\omega_{k}\right)$, which contradicts the assertion that $\sum_{k} m_{k}^{*} Z\left(\omega_{k}\right)>V^{+}(Z)$. This proves the result. 
(iii) Consider a modified primal problem where we drop the $l_{k}$ variables and the corresponding constraints for $k \in \Omega^{a}$. Correspondingly, in the dual problem, we drop the variables $\delta_{k}$ and the constraints $\delta_{k} \leq m_{k}^{*}$ for $k \in \Omega^{a}$. Note that the modified primal problem is always feasible, but the modified dual problem is infeasible. Thus, the primal problem must be unbounded. This implies that there is a marketable portfolio with cash flows that are used only in the states $\Omega^{a}$ that can be shorted to create non-marketable tranches to be sold to investors, and yields infinite profit.

(iv) As before, let $Z^{\prime}$ be the marketable security that gives the upper bound on $Z$. Arguing as before, we get $E_{q}\left[Z^{\prime}\right]<E_{m^{*}}\left[Z^{\prime}\right]$ for all $q \in \Theta$. However, because $Z^{\prime} \geq 0$, if there is a $q \geq m^{*}$, this leads to a contradiction.

Proof of Theorem 5. (i) The proof of this part follows from Theorem 4(iv). If there exists $q \in \Theta$ such that $q_{k} \geq m_{k}^{*}$ for all $k$, then the set $\Omega^{a}$ is empty. Thus, by definition of $T^{a}$, we obtain that $T^{a}$ is zero in all states in the optimal solution.

(ii) If there exists $q \in \Theta$ such that $q_{k} \leq m_{k}^{*}$ for all $k$ and $q_{k}<m_{k}^{*}$ for some $k$, then consider the solution to the dual problem, $D^{T}(J)$, obtained by setting $\lambda_{k}=m_{k}^{*}$ and $\delta_{k} \geq 0$ for all $k$. This solution is feasible and yields an objective function value of $\sum_{k} m_{k}^{*}\left(\sum_{j} w_{j} X_{j}\left(\omega_{k}\right)\right)$. Also consider the solution to the primal problem, $V^{T}(J)$, given by $Y_{k}=\sum_{j} w_{j} X_{j}\left(\omega_{k}\right)$ for all $k, l_{k}=0$ for all $k$, and $\beta_{n}=0$ for all $n$. This also gives an objective function value of $\sum_{k} m_{k}^{*}\left(\sum_{j} w_{j} X_{j}\left(\omega_{k}\right)\right)$. Since the primal objective function value is equal to the dual objective function value, these solutions are optimal. Therefore, there exists an optimal tranching solution in which $T^{m}=T^{I}=0$.

(iii) This case is the complement of the possibilities covered in (i) and (ii). Hence, the proof follows. 